\title{
Cardiovascular and Metabolic Protection by Vitamin E: A Matter of Treatment Strategy?
}

\author{
Melanie Ziegler ${ }^{1,+}$, Maria Wallert ${ }^{2,3,+}$, Stefan Lorkowski ${ }^{2,3}$ (1) and Karlheinz Peter ${ }^{4,5,6,7, *}$ \\ 1 Department of Cardiology and Angiology, Internal Medicine III, University Clinic of Tübingen, \\ 72076 Tübingen, Germany; melanie.ziegler@med.uni-tuebingen.de \\ 2 Institute of Nutritional Sciences, Friedrich Schiller University, 07743 Jena, Germany; \\ maria.wallert@uni-jena.de (M.W.); stefan.lorkowski@uni-jena.de (S.L.) \\ 3 Competence Cluster for Nutrition and Cardiovascular Health (nutriCARD) Halle-Jena-Leipzig, Germany \\ 4 Atherothrombosis and Vascular Biology Laboratory, Baker Heart and Diabetes Institute, \\ 75 Commercial Road, Melbourne, VIC 3004, Australia \\ 5 Department of Medicine and Immunology, Monash University, Melbourne, VIC 3800, Australia \\ 6 Department of Cardiometabolic Health, University of Melbourne, Melbourne, VIC 3800, Australia \\ 7 Department of Cardiology, The Alfred Hospital, Melbourne, VIC 3800, Australia \\ * Correspondence: karlheinz.peter@baker.edu.au; Tel.: +61(3)-8532-1490 \\ + These authors contributed equally.
}

Received: 28 August 2020; Accepted: 23 September 2020; Published: 29 September 2020

check for updates

\begin{abstract}
Cardiovascular diseases (CVD) cause about 1/3 of global deaths. Therefore, new strategies for the prevention and treatment of cardiovascular events are highly sought-after. Vitamin E is known for significant antioxidative and anti-inflammatory properties, and has been studied in the prevention of CVD, supported by findings that vitamin E deficiency is associated with increased risk of cardiovascular events. However, randomized controlled trials in humans reveal conflicting and ultimately disappointing results regarding the reduction of cardiovascular events with vitamin E supplementation. As we discuss in detail, this outcome is strongly affected by study design, cohort selection, co-morbidities, genetic variations, age, and gender. For effective chronic primary and secondary prevention by vitamin E, oxidative and inflammatory status might not have been sufficiently antagonized. In contrast, acute administration of vitamin E may be more translatable into positive clinical outcomes. In patients with myocardial infarction (MI), which is associated with severe oxidative and inflammatory reactions, decreased plasma levels of vitamin $\mathrm{E}$ have been found. The offsetting of this acute vitamin E deficiency via short-term treatment in MI has shown promising results, and, thus, acute medication, rather than chronic supplementation, with vitamin $\mathrm{E}$ might revitalize vitamin $\mathrm{E}$ therapy and even provide positive clinical outcomes.
\end{abstract}

Keywords: vitamin E; cardiovascular disease; myocardial infarction; risk factors; treatment strategy

\section{Introduction}

Cardiovascular diseases (CVD) such as atherosclerosis are a major cause of mortality and morbidity worldwide. Multiple factors are involved in the complex etiology of atherosclerosis. One of the most important factors that drives atherosclerosis and its complications, such as myocardial infarction (MI) and stroke, is inflammation. Inflammation plays a pivotal role in both the initial, as well as the advanced, phases of atherosclerosis, including plaque destabilization and ultimate rupture. In particular, the advanced phase of atherosclerosis is characterized by a high degree of inflammation that includes high-level production of reactive oxygen species (ROS), due to excessive oxidative stress [1,2]. One of the major initial inducers of oxidative stress in atherosclerosis is pathological shear stress levels and flow patterns [3]. An imbalance between oxidants and antioxidants enhances oxidative stress and promotes 
oxidation of circulating low-density lipoprotein cholesterol (LDL-C). Elevated oxidized LDL-C (oxLDL) acts as a damage-associated molecular pattern and damages the endothelium further, and is also internalized by monocytes/macrophages, which consequently transform into foam cells and amplify the inflammatory process further [2]. Consequently, the secretion of pro-inflammatory chemokines and cytokines, and the activation of immune cells, exacerbate the progression of atherosclerosis. Antioxidants, either endogenous antioxidants like superoxide dismutase (SOD), catalase, glutathione (GSH) and GSH peroxidase, or antioxidants derived from dietary sources like vitamin A, C, and E, are needed to scavenge free radicals and other toxic radicals [4]. Patients suffering from inflammatory diseases often present with decreased levels of antioxidants, due to either insufficient dietary intake or increased demand for antioxidants [5]. Vitamin $\mathrm{E}$ is a very potent antioxidant substance, and shows high anti-inflammatory properties [6,7]. Therefore, vitamin E, particularly the $\alpha$-tocopherol $(\alpha-\mathrm{TOH})$ form, has been suggested as a promising candidate in the prevention of CVD. However, enthusiastic research on vitamin $\mathrm{E}$ in large clinical trials has only resulted in controversial and mostly discouraging outcomes, and ultimately has not provided evidence for overall beneficial effects of vitamin E in CVD, with a few exceptions, as discussed below. The aim of the present review is to critically summarize the data available on vitamin $\mathrm{E}$ supplementation in diseases in general and systematically investigate potential reasons for the observed conflicting results, and we also provide a perspective on what we have learned from the past trials for future trials. We ultimately redirect the focus from chronic vitamin E supplementation to short-term vitamin E medication in acute clinical settings caused by high inflammatory and oxidative stress, such as MI.

\section{Vitamin E Characterization}

Vitamins are micronutrients essential for the maintenance of metabolic functions, but not necessarily for energy regeneration. Humans are not able to synthesize vitamins by themselves, so vitamins need to be supplied from food. The function of vitamin $\mathrm{E}$ as a vitamin was first discovered in 1922 by Evans and Bishop, demonstrating its relevance as a fertility factor in rats [8]. Later the $\alpha-\mathrm{TOH}$ form, more precisely the stereoisomere $R R R-\alpha-\mathrm{TOH}$, of vitamin $\mathrm{E}$ was identified to convey this property. The genetic disorder ataxia with vitamin E deficiency results in low levels of $\alpha$-TOH, due to a defect in the $\alpha$-tocopherol transport protein ( $\alpha$-TTP). Only the $R R R-\alpha$-TOH form serves as a proper treatment for this disease. Therefore, there is an ongoing discussion whether only $R R R-\alpha-\mathrm{TOH}$ conveys the vitamin function and other forms of vitamin E would not [9].

\subsection{Different Forms of Vitamin E}

The group of vitamin $\mathrm{E}$ consists of $\alpha-, \beta-, \gamma-$, and $\delta$-forms of tocopherols $(\mathrm{TOH})$ and tocotrienols (T3) [9] (Figure 1). The course of vitamin E digestion follows in general the course of coexisting lipid compounds. Pancreatic and intestinal enzymatic digestion followed by circulation and distribution to the liver and non-hepatic tissues is the same for all vitamin $\mathrm{E}$ forms. To date, no discrimination of $\alpha$-TOH over non- $\alpha$-TOH forms is known for intestinal absorption [10], whereas $\alpha$-TTP in the liver discriminates in favor of $\alpha-\mathrm{TOH}$. Consequently, $\alpha-\mathrm{TOH}$ is the most abundant form of vitamin $\mathrm{E}$ in healthy humans [11]. In humans, circulating $\alpha-\mathrm{TOH}$ concentrations of $>12 \mathrm{mmol} / \mathrm{L}$ are defined as adequate, whereas $<12 \mathrm{mmol} / \mathrm{L}$ represents a marginal and $<9 \mathrm{mmol} / \mathrm{L}$ a severe deficiency [12,13]. Today, biological activity is best investigated for $\alpha-\mathrm{TOH}$. However, the biological relevance of non- $\alpha-\mathrm{TOH}$ forms of vitamin $\mathrm{E}$ is increasingly becoming the focus of research, due to observed, at least in part, distinct properties compared to $\alpha-\mathrm{TOH}$. 

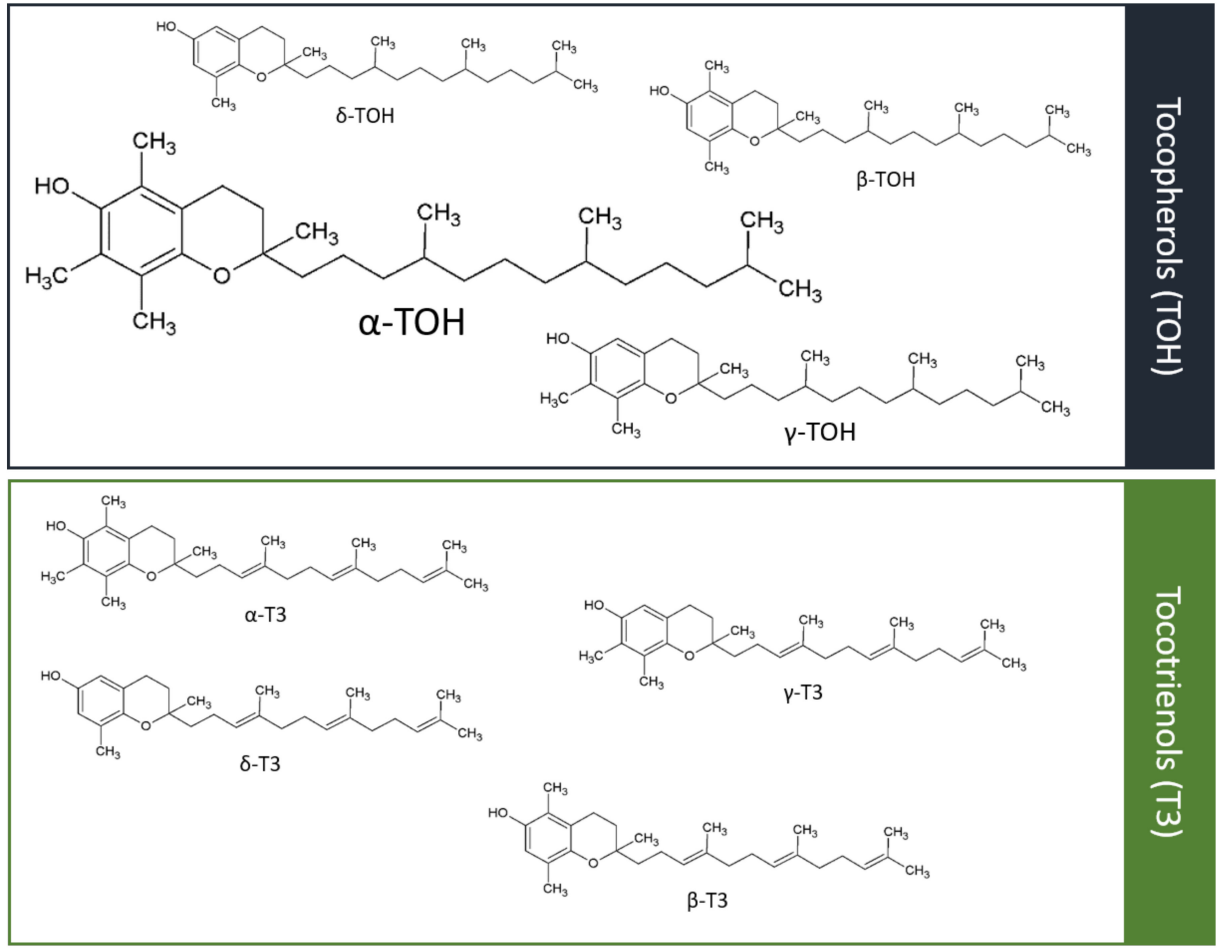

Figure 1. Different forms of vitamin E. The vitamin E group consists of eight different forms, $\alpha_{-}^{-}, \beta_{-}^{-}, \gamma^{-}$, $\delta$-tocopherol (TOH) and their respective tocotrienols (T3), $\alpha$-TOH being the most prominent form in human nutrition and in the human body. Other forms of vitamin E, such as tocomonoenols, are known, but are not relevant in human nutrition, and are therefore not addressed in this review.

\subsection{Metabolism of Vitamin $E$}

Hepatic degradation of all vitamin $E$ forms is inversely regulated to the amount of vitamin E supplied in the diet, thus, protecting from excessive accumulation of vitamin E [14]. $\alpha$-TTP preferentially binds to $\alpha-\mathrm{TOH}$ in contrast to non- $\alpha-\mathrm{TOH}$ forms, which protects $\alpha-\mathrm{TOH}$ from excessive degradation in the liver and excretion via feces and urine $[15,16]$. $\alpha-\mathrm{TOH}$ is mainly released into the circulation by the liver in nascent lipoproteins, such as very-low-density lipoprotein (VLDL), whereas non- $\alpha$-TOH forms are primarily metabolically degraded followed by their excretion $[10,17,18]$. Side-chain truncation of vitamin $\mathrm{E}$ initiates the metabolism by cytochrome P450 (CYP) 4F2/3A4-dependent $\omega$-hydroxylation, resulting in the formation of long-chain metabolites (LCM) of $\alpha-\mathrm{TOH}, \alpha-13^{\prime}-\mathrm{OH}[19,20]$ and $\alpha-13^{\prime}-\mathrm{COOH}$. The catabolic end-product of vitamin E degradation is $\alpha$-carboxyethyl hydrochroman ( $\alpha$-CEHC) [21]. Excessive supplementation of $\alpha$-TOH increases $\alpha$-TOH plasma levels and enhances degradation of both non- $\alpha-\mathrm{TOH}$ forms and $\alpha-\mathrm{TOH}$ itself, and subsequently the excretion of the respective CEHC [22]. Hence, $\alpha-\mathrm{CEHC}$ is used as a marker for $\alpha-\mathrm{TOH}$ status in healthy humans $[23,24]$. Although catabolism is more rapid for T3s than TOHs and varies within the TOHs, the metabolic pathway is the same [21].

\subsection{Relevance and Evidence of Vitamin E as an Antioxidant/Pro-Oxidant and Its Non-Antioxidative Properties}

The vitamin E molecules consist of three functionally distinct domains: the functional domain, the signaling domain, and the hydrophobic domain [25], mediating the antioxidative capacity and non-antioxidative effects of vitamin E. All vitamin E forms have the hydroxyl group at position C6 in common, which results in similar antioxidative capacity for all vitamin E forms [26]. Vitamin E, more precisely $\alpha-\mathrm{TOH}$, protects or promotes oxidation depending on prevailing oxidative conditions. Under strong oxidative conditions, $\alpha-\mathrm{TOH}$ is known as the most important lipid-soluble radical chain-breaking antioxidant, protecting phospholipids in cell membranes and plasma lipoproteins against peroxidation of polyunsaturated fatty acids (PUFA), at least in vitro [7,27]. Under mild oxidative 
conditions, the tocopheroxyl radical is regenerated to intact tocopherol by co-antioxidants [28]. The most important co-antioxidant is ascorbic acid, which subsequently forms an ascorbyl radical under the regeneration of $\alpha-\mathrm{TOH}$. With a deficiency of co-antioxidants [28] or high concentrations of $\alpha-\mathrm{TOH}$, $\alpha-\mathrm{TOH}$ has been discussed to promote pro-oxidant properties. Even in vivo vitamin $\mathrm{E}$ supplementation was described as a potential risk factor for increasing gastrointestinal symptoms and total mortality [29], possibly induced by increased oxidative activity in plasma [30]. However, a study by Miller et al. reporting increased mortality caused by $\alpha-\mathrm{TOH}$ supplementation was controversially discussed [31]. Subsequent evaluation using different methodological approaches to meta-analysis did not show a causal relationship between vitamin E supplementation and increased mortality [31]. In addition, in studies in healthy subjects not showing increased oxidative stress, supplementation of $\alpha$-TOH did not affect markers of oxidative damage [32], while high-dose supplementation of $\alpha$-TOH even decreased oxidative stress in hypercholesterolemic patients [33,34]. So far, no clinical trial has observed adverse effects of vitamin E supplementation in healthy subjects [35].

In the early 1950s, Hickman and Harris first mentioned properties of vitamin E independent from its antioxidative capacity [36]. Decades later, the research of Azzi and colleagues established several working hypotheses regarding the non-antioxidative properties of $\alpha-\mathrm{TOH}$ [37]. To date, $\alpha-\mathrm{TOH}$ and non- $\alpha-\mathrm{TOH}$ forms are known to regulate the expression of genes and proteins, the activity of enzymes, signaling cascades within uptake, transport, degradation, metabolism and excretion of vitamin E forms, lipoprotein uptake, and inflammation, to name only a few of their functions [27]. These non-antioxidative properties control several events in atherosclerosis, such as the inhibition of smooth muscle cell (SMC) proliferation, the preservation of endothelial integrity, the inhibition of monocyte-endothelial adhesion, the inhibition of monocyte ROS and cytokine release, and the inhibition of platelet adhesion and aggregation [37]. In addition, scavenger receptors, adhesion molecules, and collagenase seem to be under the non-antioxidant control of $\alpha-\mathrm{TOH}$ [38].

\section{Cardiovascular Diseases}

\subsection{Atherogenesis, Atheroprogression, and Plaque Rupture}

The earliest event in atherogenesis is endothelial dysfunction triggered by a number of insults including disturbed flow patterns and low shear stress, arterial flow, hypertension, homocysteinemia, hyperlipidemia, diabetes, physical injury, and ROS [39]. Endothelial dysfunction leads to a disrupted endothelial barrier, contributing to lipid accumulation within the intima and so-called fatty streak formation. The inflamed endothelium expresses adhesion molecules and secretes chemokines, leading to leukocyte recruitment. At this point, monocytes transmigrate through the endothelium into the intima, differentiate into macrophages, absorb the lipoproteins, and become foam cells. The last key step is the degradation of the extracellular matrix, and then an atherosclerotic plaque is formed [40]. A stable atherosclerotic plaque has a lipid-rich necrotic core encapsulated by a thick and stable fibrous cap. As the plaque progresses, the core becomes more necrotic and larger in size, and more intraplaque hemorrhage occurs, as well as thinning of the fibrous cap; this advanced plaque is called an unstable or vulnerable plaque [41]. At this stage, the plaque is very fragile with a high risk of rupture. Plaque rupture exposes thrombogenic components, leading to thrombosis, which can then cause occlusion of the respective or a downstream artery resulting in an acute MI or stroke [42-44].

\subsection{Cardiovascular Events}

CVD are the leading cause of mortality worldwide, representing 31\% of all global deaths [45]. CVD include coronary artery disease, cerebrovascular disease, peripheral arterial disease, deep vein thrombosis, and pulmonary embolism. Most cardiovascular events and deaths can be explained by risk factors such as hypertension, dyslipidemia, diabetes, obesity, unhealthy diet, physical inactivity, and smoking. Strikingly, epidemiological studies have shown that $75 \%$ of premature CVD are preventable by early intervention $[46,47]$. Coronary heart disease (CHD), also called ischemic heart 
disease (IHD) and coronary artery disease, is the CVD with the highest morbidity and mortality worldwide [45,47]. In CHD, the blood supply is mostly reduced or blocked due to atherosclerotic plaques and its complications, particularly an acute atherothrombotic event in the coronary arteries. The dynamic nature of CHD results in various clinical manifestations which can be categorized as either acute coronary syndrome, such as ST-elevation MI (STEMI) and non-ST-elevation MI (NSTEMI), or chronic coronary syndrome, such as stable angina pectoris [48].

Myocardial infarction is the single leading cause of death globally [45]. It is typically defined by chest pain, abnormal cardiac biomarkers (typically troponin I or T), and potentially typical electrocardiogram (ECG) changes (ST-elevation) [49]. The treatment of MI with timely percutaneous coronary intervention (PCI) or pharmacological thrombolysis has contributed to substantial improvement in the outcome of patients suffering from MI. However, paradoxically, restoration of coronary blood flow causes further myocardial damage, referred to as ischemia/reperfusion injury [50]. The early phase of ischemia/reperfusion injury is characterized by extensive tissue damage to the myocardium caused by inflammatory and oxidative stress responses leading to immune cell infiltration, as well as production and release of pro-inflammatory cytokines and chemokines. Imaging the area of oxidative stress defines the ischemic and reperfused myocardium very well [51]. Following this, the late phase consists of wound healing and fibrotic repair [52].

\section{Vitamin E and Risk Factors for Cardiovascular Events}

The association between vitamin $\mathrm{E}$ and risk factors for cardiovascular events will be discussed in detail in the following chapter, and is summarized in Figure 2 and Table 1.

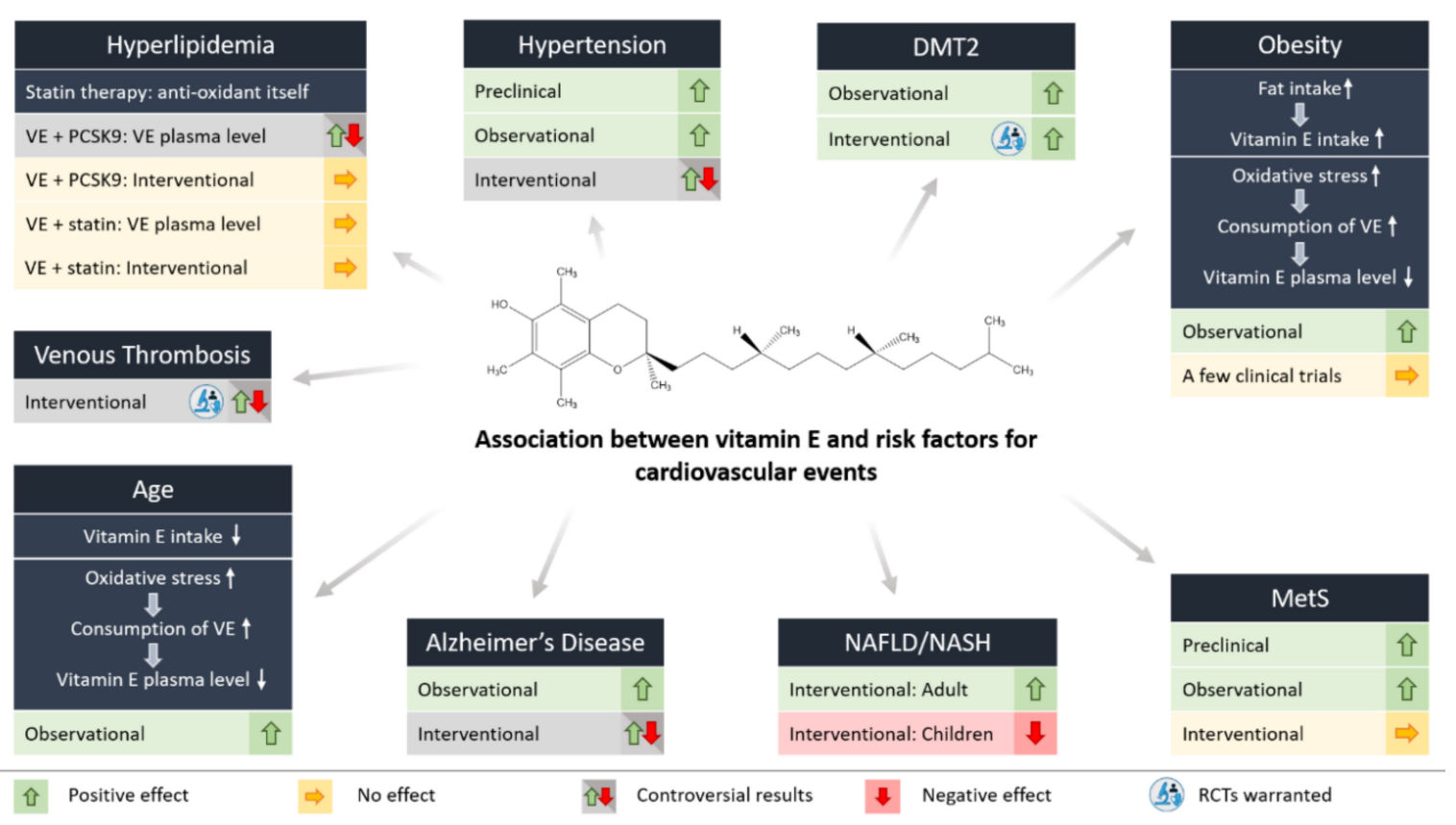

Figure 2. Association between vitamin $\mathrm{E}$ and risk factors for cardiovascular events. Correlations between vitamin E plasma level and effects of vitamin E supplementation on single risk factors for cardiovascular events are shown. Risk factors presented here are either dependent (hyperlipidemia, diabetes mellitus type 2 (DMT2), obesity, age, Alzheimer's disease, non-alcoholic fatty liver disease (NAFLD), non-alcoholic steatohepatitis (NASH), metabolic syndrome (MetS)) or independent (hypertension, venous thrombosis) of oxidative processes and inflammation. Most of the risk factors are positively affected by vitamin E, showing the beneficial potential of vitamin $\mathrm{E}$ in cardiovascular events. However, randomized clinical trials have revealed controversial results or no effect. Abbreviations used in the figure: vitamin E, VE. 
Table 1. Vitamin E and Risk Factors for Cardiovascular Events.

\begin{tabular}{|c|c|c|c|c|c|}
\hline Risk Factor & Type of Study & Author & Participants & Endpoints & Vitamin E Dosage \\
\hline \multirow[t]{6}{*}{$\begin{array}{l}\text { Hypertension } \\
\text { SBP (systolic blood } \\
\text { pressure) } \\
\text { DPB (diastolic blood } \\
\text { pressure) }\end{array}$} & Observational & Kuwabara et al. [53] & $n=3507$ & $\begin{array}{l}\text { higher vitamin } E \text { intake is associated with } \\
\text { a lower percentage of subjects with } \\
\text { hypertension }\end{array}$ & \\
\hline & Interventional & Boshtam et al. [54] & $\begin{array}{l}n=70 \\
\text { mild hypertensive patients }\end{array}$ & $\begin{array}{l}\text { Significant decrease in SBP and DBP } \\
\text { (mainly in SBP) }\end{array}$ & $134 \mathrm{mg}$ per day (200 IU) for 27 weeks \\
\hline & Interventional & Tmj et al. [55] & $\begin{array}{l}n=60 \\
\text { mild hypertensive subjects }\end{array}$ & decrease in blood pressure & $134 \mathrm{mg}$ (200 IU) per day for 12 weeks \\
\hline & Interventional & Palumbo et al. [56] & $\begin{array}{l}n=142 \\
\text { treated hypertensive patients }\end{array}$ & $\begin{array}{l}\text { no clinically relevant effect on blood } \\
\text { pressure }\end{array}$ & $300 \mathrm{mg}$ per day for 12 weeks \\
\hline & Interventional & Mihalj et al. [57] & $\begin{array}{l}n=57 \\
\text { treated hypertensive patients }\end{array}$ & $\begin{array}{l}\text { no further effect of vitamin } \mathrm{E} / \mathrm{C} \\
\text { supplementation }\end{array}$ & $\begin{array}{l}720 \mathrm{mg} \text { vitamin } \mathrm{E} \text { and } 25 \mathrm{mg} \text { vitamin } \mathrm{C} \\
\text { per day for } 8 \text { weeks }\end{array}$ \\
\hline & Interventional & Barbagallo et al. [58] & $\begin{array}{l}n=12 \\
\text { hypertensive patients }\end{array}$ & $\begin{array}{l}\text { no effect of vitamin } E \text { treatment on } \\
\text { SBP or DBP }\end{array}$ & $600 \mathrm{mg}$ vitamin $\mathrm{E}$ per day for 4 weeks \\
\hline \multirow{6}{*}{$\begin{array}{l}\text { Hyperlipidemia } \\
\text { Hypercholesterolemic } \\
\text { (HC) }\end{array}$} & & & & & \\
\hline & $\begin{array}{l}\text { Observational } \\
\text { Interventional }\end{array}$ & Cangemi et al. [59] & $\begin{array}{l}n=30 \\
\text { HC patients } \\
n=20 \\
\text { healthy subjects } \\
n=30\end{array}$ & $\begin{array}{l}\text { lower vitamin E plasma level in HC } \\
\text { patients vs. healthy subjects } \\
\text { administration of atorvastatin restored } \\
\text { vitamin E/TC plasma level }\end{array}$ & $10 \mathrm{mg}$ atorvastatin per day for 30 days \\
\hline & Observational & Shin et al. [60] & $\begin{array}{l}n=76 \\
\text { HC patients }\end{array}$ & $\begin{array}{l}\text { increased } \alpha-\mathrm{TOH} / \text { lipid plasma level in } \mathrm{HC} \\
\text { patients }\end{array}$ & $20-40 \mathrm{mg}$ simvastatin per day for 8 weeks \\
\hline & Observational & Blom et al. [61] & $\begin{array}{l}n=738 \\
\text { HC patients }\end{array}$ & $\begin{array}{l}\text { increased vitamin E/TC plasma level in } \\
\text { evolocumab (anti- PCSK9 } \\
\text { antibody)-treated patients from baseline to } \\
\text { week } 52\end{array}$ & $\begin{array}{l}10 \text { or } 80 \mathrm{mg} \text { atorvastatin per day or } 80 \mathrm{mg} \\
\text { atorvastatin plus } 10 \mathrm{mg} \text { ezetimibe per day } \\
\text { for } 52 \text { weeks, } 420 \mathrm{mg} \text { Evolocumab or } \\
\text { placebo for } 8 \text { weeks }\end{array}$ \\
\hline & Interventional & Lui et al. [62] & $\begin{array}{l}n=19 \\
\text { HC patients }\end{array}$ & $\begin{array}{l}\text { increased vitamin E/LDL-C plasma level in } \\
\text { atorvastatin-treated HC patients }\end{array}$ & $10 \mathrm{mg}$ atorvastatin per day for 5 months \\
\hline & Interventional & Leonard et al. [63] & $\begin{array}{l}n=44 \\
\text { HC patients }\end{array}$ & $\begin{array}{l}\text { vitamin E supplementation did not alter } \\
\text { cholesterol levels under statin therapy }\end{array}$ & $\begin{array}{l}268 \mathrm{mg}(400 \mathrm{IU}) \\
\text { vitamin } \mathrm{E} \text { per day or placebo for } 12 \text { weeks }\end{array}$ \\
\hline \multirow[t]{3}{*}{ Thrombosis } & & & & & \\
\hline & Interventional & Glynn et al. [64] & $n=39,876$ women aged 45 and older & $\begin{array}{l}\text { women taking vitamin } E \text { were } 21 \% \text { less } \\
\text { likely to suffer a venous thromboembolism }\end{array}$ & $\begin{array}{l}\text { Vitamin E }(540 \mathrm{mg} \text { ) or a placebo on } \\
\text { alternate days over a } 10 \text {-year period. }\end{array}$ \\
\hline & Interventional & Vuckovic et al. [65] & $\begin{array}{l}2506 \text { patients with venous thrombosis, } \\
2506 \text { partner controls, and } 2684 \\
\text { random-digit-dialing (RDD) controls } \\
n=96 \text { patients supplemented with vitamin } \mathrm{E}\end{array}$ & $\begin{array}{l}\text { No association of vitamin } \mathrm{E} \\
\text { supplementation with a reduced venous } \\
\text { thrombosis risk }\end{array}$ & $\begin{array}{l}\text { No information was obtained on the } \\
\text { dosage of vitamin } E \text { intake }\end{array}$ \\
\hline
\end{tabular}


Table 1. Cont.

\begin{tabular}{|c|c|c|c|c|c|}
\hline Risk Factor & Type of Study & Author & Participants & Endpoints & Vitamin E Dosage \\
\hline \multicolumn{6}{|l|}{ Age } \\
\hline & Observational & Ortega et al. [66] & $\begin{array}{l}n=120 \\
\text { aged subjects ( } 65-91 \text { years) }\end{array}$ & $\begin{array}{l}\text { Lower vitamin } \mathrm{E} \text { intake and } \alpha \text {-TOH/TC } \\
\text { plasma level correlates with cognitive } \\
\text { impairment in elderly }\end{array}$ & - \\
\hline & Observational & Vatassery et al. [67] & 48 healthy male volunteers aged $24-91$ years & $\begin{array}{l}\alpha \text {-TOH plasma level remained unchanged, } \\
\text { decreased } \alpha \text {-TOH level in platelets of } \\
\text { elderly subjects }\end{array}$ & - \\
\hline & Observational & Capuron et al. [68] & $\begin{array}{l}n=69 \\
\text { aged subjects ( } 73-86 \text { years) }\end{array}$ & $\begin{array}{l}\text { Lower } \alpha \text {-TOH plasma level in subjects } \\
\text { with poor physical and mental health } \\
\text { status }\end{array}$ & - \\
\hline & Observational & Requejo et al. [69] & $\begin{array}{l}n=120 \\
\text { aged subjects (65-91 years) }\end{array}$ & $\begin{array}{l}95.2 \% \text { are below recommendations of } \\
\text { a-TOH intake }\end{array}$ & - \\
\hline & Observational & Rudman et al. [70] & $\begin{array}{l}n=34 \\
\text { eating-dependent nursing home residents }\end{array}$ & $\begin{array}{l}\text { The vast majority did not receive } \\
\text { micronutrient supplements }\end{array}$ & 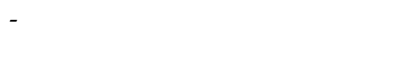 \\
\hline & Interventional & De la Fuente et al. [71] & $\begin{array}{l}n=33 \\
\text { aged subjects ( } 65-75 \text { years) } \\
n=30 \text { controls ( } 25-35 \text { years })\end{array}$ & $\begin{array}{l}\alpha-\mathrm{TOH} \text { improves immune functions and } \\
\text { therefore health in aged people }\end{array}$ & $200 \mathrm{mg} \alpha-\mathrm{TOH}$ per day for 3 months \\
\hline \multicolumn{6}{|l|}{ Obesity } \\
\hline & Observational & Silva et al. [72] & $\begin{array}{l}n=33 \\
\text { overweight adolescents } \\
n=42 \\
\text { obese adolescents } \\
n=75 \\
\text { healthy adolescents (10-15 years) }\end{array}$ & $\begin{array}{l}\text { Crude and energy-adjusted intake of } \\
\text { vitamin E positively correlate with BMI, } \\
\text { but not with plasma level of vitamin E; } \\
\alpha \text {-TOH/LDL-C and } \alpha \text {-TOH/TC decrease in } \\
\text { obese and overweight adolescents }\end{array}$ & - \\
\hline & Observational & Mehmetoglu et al. [73] & $\begin{array}{l}n=98 \text { obese patients } \\
n=78 \text { healthy subjects ( } 18-65 \text { years) }\end{array}$ & $\begin{array}{l}\text { decreased } \alpha-\mathrm{TOH} / \mathrm{TC}+\mathrm{TG} \text { plasma level in } \\
\text { obese subjects }\end{array}$ & - \\
\hline & Observational & Kljno et al. [74] & $\begin{array}{l}n=17 \text { obese girls } \\
n=7 \text { healthy girls } \\
\text { (8-15 years) }\end{array}$ & $\begin{array}{l}\alpha-\mathrm{TOH} / \text { total lipids decreased in plasma } \\
\text { and in LDL in obese subjects }\end{array}$ & - \\
\hline & Observational & Strauss et al. [75] & $\begin{array}{l}n=6139 \text { children ( } 6-19 \text { years) enrolled in the } \\
\text { NHANES III }\end{array}$ & $\begin{array}{l}\text { decreased } \alpha-\mathrm{TOH} / \mathrm{TC}+\mathrm{TG} \text { plasma level in } \\
\text { obese subjects }\end{array}$ & - \\
\hline & Observational & Molnar et al. [76] & $\begin{array}{l}n=15 \text { obese adolescents } \\
n=16 \text { healthy adolescents } \\
\text { (13-16 years) }\end{array}$ & $\begin{array}{l}\alpha-\mathrm{TOH} / \mathrm{TC}+\mathrm{TG} \text { plasma level remained } \\
\text { unchanged in obese subjects }\end{array}$ & - \\
\hline & Observational & Gunanti et al. [77] & $\begin{array}{l}6139 \text { children ( } 8-15 \text { years) enrolled in the } \\
\text { 2001-2004 NHANES }\end{array}$ & $\begin{array}{l}\text { Adequate plasma level of } \alpha \text {-TOH/TC are } \\
\text { associated with reduced probability of } \\
\text { overweight }\end{array}$ & - \\
\hline
\end{tabular}


Table 1. Cont

\begin{tabular}{|c|c|c|c|c|c|}
\hline Risk Factor & Type of Study & Author & Participants & Endpoints & Vitamin E Dosage \\
\hline DMT2 & & & & & \\
\hline \multirow[t]{12}{*}{$\begin{array}{l}\text { DMT2 (Diabetes } \\
\text { mellitus type 2) }\end{array}$} & Observational & Schneider et al. [78] & $\begin{array}{l}n=31 \text { DMT2 patients ( } 46-79 \text { years) } \\
n=31 \text { control subjects ( } 38-63 \text { years) }\end{array}$ & $\begin{array}{l}\text { VLDLs and LDLs of DMT2 patients } \\
\text { contained fewer vitamin E molecules } \\
\text { compared to controls due to PLPT }\end{array}$ & - \\
\hline & Observational & Galvan et al. [79] & $\begin{array}{l}n=12 \text { male DMT2 patients ( } 49-54 \text { years) } \\
n=19 \text { control subjects ( } 29-34 \text { years) }\end{array}$ & $\begin{array}{l}\text { Insulin infusion decreased } \alpha \text {-TOH/LDL-C } \\
\text { plasma level }\end{array}$ & - \\
\hline & $\begin{array}{l}\text { Observational } \\
\text { (meta-analysis) }\end{array}$ & Kollerits et al. [80] & $n=20,136$ subjects & $\begin{array}{l}\text { Vitamin E-binding protein afamin is an } \\
\text { independent predictor for DMT2 incidence, } \\
\text { increase in afamin is associated with } \\
\text { prevalence DMT2 }\end{array}$ & - \\
\hline & $\begin{array}{l}\text { Observational/ } \\
\text { Interventional }\end{array}$ & Mayer-Davis et al. [81] & $\begin{array}{l}n=895 \text { non-diabetic adults ( } 45-65 \text { years) } \\
\text { ( } n=318 \text { non-supplement users and } n=577 \\
\text { supplement users) }\end{array}$ & $\begin{array}{l}\alpha-\mathrm{TOH} \text { plasma level is decreased in DMT2 } \\
\text { patients and correlates with diabetes } \\
\text { incidence, but not the nutritional } \\
\text { intake/use of supplements }\end{array}$ & $-/$ not defined \\
\hline & Observational & Škrha et al. [82] & $\begin{array}{l}n=62 \text { DMT2 patients ( } 49-64 \text { years) } \\
n=20 \text { controls subjects }\end{array}$ & $\begin{array}{l}\text { decreased } \alpha-\mathrm{TOH} / \mathrm{TC}, \mathrm{TG} \text { serum level in } \\
\text { diabetic patients with macroangiopathy } \\
\text { versus without vascular changes }\end{array}$ & - \\
\hline & Observational & Salonen et al. [83] & $n=944$ male healthy subjects ( $42-60$ years) & $\begin{array}{l}\text { decreased } \alpha \text {-TOH plasma levels associated } \\
\text { with increase diabetes risk }\end{array}$ & - \\
\hline & Observational & Eljaoudi et al. [84] & $\begin{array}{l}n=60 \text { DMT2 patients } \\
n=40 \text { healthy subjects ( } 31-76 \text { years) }\end{array}$ & decreased $\alpha-\mathrm{TOH}$ plasma level in DMT2 & - \\
\hline & Observational & Nourooz-Zadeh et al. [85] & $\begin{array}{l}n=87 \text { DMT2 patients } \\
n=41 \text { healthy subjects ( } 17-86 \text { years) }\end{array}$ & $\begin{array}{l}\text { decreased } \alpha-\mathrm{TOH} / \mathrm{TC} \text { plasma level in } \\
\text { DMT2 }\end{array}$ & - \\
\hline & Observational & Mehmetoglu et al. [73] & $\begin{array}{l}n=98 \text { obese subjects } \\
n=78 \text { healthy subjects } \\
\text { (18-65 years) }\end{array}$ & $\begin{array}{l}\text { no correlation of } \alpha-\mathrm{TOH} / \mathrm{TC}+\mathrm{TG} \text { plasma } \\
\text { level and insulin resistance in obese } \\
\text { subjects }\end{array}$ & (20 \\
\hline & Interventional & Rafighi et al. [86] & $n=170$ DMT2 patients ( $30-60$ years) & $\begin{array}{l}\text { Vitamin E supplementation decreased } \\
\text { blood glucose level, antioxidative capacity, } \\
\text { (increased SOD and GSH enzyme activity), } \\
\text { oxidative stress and insulin resistance }\end{array}$ & $\begin{array}{l}200 \mathrm{mg}(300 \mathrm{IU}) \text { vitamin } \mathrm{E}(/ \text { day }) \text { and } 267 \\
\text { mg vitamin C per day for } 3 \text { months }\end{array}$ \\
\hline & Interventional & Manning et al. [87] & $n=80$ healthy subjects ( $38-57$ years) & $\begin{array}{l}\text { Vitamin E supplementation decreased } \\
\text { inflammatory processes, fasting plasma } \\
\text { glucose and improved insulin sensitivity in } \\
\text { overweight subjects }\end{array}$ & $\begin{array}{l}537 \mathrm{mg}(800 \mathrm{IU}) \text { vitamin E per day or } \\
\text { placebo for } 3 \text { months }\end{array}$ \\
\hline & $\begin{array}{l}\text { Interventional } \\
\text { (Meta-analysis) }\end{array}$ & Xu et al. [88] & $n=714$ subjects & $\begin{array}{l}\text { vitamin E supplementation did not change } \\
\text { glycemic control (HbA1c, fasting glucose, } \\
\text { fasting insulin) }\end{array}$ & $\begin{array}{l}\text { 134-1074 mg (200-1600 IU) per day for } \\
6-27 \text { weeks }\end{array}$ \\
\hline
\end{tabular}


Table 1. Cont.

\begin{tabular}{|c|c|c|c|c|c|}
\hline Risk Factor & Type of Study & Author & Participants & Endpoints & Vitamin E Dosage \\
\hline \multicolumn{6}{|l|}{ Fatty Liver Disease } \\
\hline & Observational & Erhardt et al. [89] & $\begin{array}{l}n=50 \text { NASH patients } \\
n=40 \text { healthy controls }\end{array}$ & $\begin{array}{l}\text { decreased } \alpha \text {-TOH plasma levels in NASH } \\
\text { patients }\end{array}$ & - \\
\hline & Observational & Machado et al. [90] & $\begin{array}{l}n=43 \text { NASH patients } \\
n=33 \text { healthy controls } \\
\text { (27-68 years) }\end{array}$ & $\begin{array}{l}\text { increased } \alpha \text {-TOH plasma levels in NASH } \\
\text { patients }\end{array}$ & - \\
\hline & Interventional & Violet et al. [91] & $\begin{array}{l}n=6 \text { female NASH patients }(33-53 \text { years) } \\
n=10 \text { female healthy controls ( } 19-35 \text { years) }\end{array}$ & $\begin{array}{l}\text { alteration of } \alpha \text {-TOH kinetics in women } \\
\text { with obesity-associated hepatosteatosis } \\
\text { compared to healthy controls, decreased } \\
\text { release of } \alpha \text {-TOH from the liver, lower } \\
\alpha-\mathrm{TOH} \text { plasma level }\end{array}$ & $2 \mathrm{mg} \alpha$-TOH once \\
\hline & Interventional & Sanyal et al. [92] & $\begin{array}{l}n=167 \text { NASH patients }(n=83 \text { placebo, } \\
n=84 \alpha-\mathrm{TOH}, 34-59 \text { years })\end{array}$ & $\begin{array}{l}\alpha-\text { TOH supplementation improves ALT, } \\
\text { AST, lobular inflammation and NASH } \\
\text { compared to placebo treated group }\end{array}$ & $\begin{array}{l}537 \mathrm{mg}(800 \mathrm{IU}) \alpha-\mathrm{TOH} \text { per day or placebo } \\
\text { for } 2 \text { years }\end{array}$ \\
\hline & Interventional & Lavine et al. [93] & $n=11 \mathrm{NASH}$ patients ( $<16$ years $)$ & $\begin{array}{l}\alpha \text {-TOH supplementation decreased ALT, } \\
\text { AST, ALP }\end{array}$ & $\begin{array}{l}268-805 \mathrm{mg}(400-1200 \mathrm{IU}) \alpha-\mathrm{TOH} \text { for } \\
4-10 \text { months }\end{array}$ \\
\hline \multicolumn{6}{|l|}{ MetS } \\
\hline & Observational & Ford et al. [94] & $\begin{array}{l}\text { MetS patients and healthy controls from } \\
\text { NHANES III ( } \geq 20 \text { years) }\end{array}$ & lower $\alpha$-TOH plasma level in MetS patients & - \\
\hline & Observational & Beydoun et al. [95] & $\begin{array}{l}n=3008-9099 \text { participants from NHANES } \\
2001-2006 \text { (20-85 years) }\end{array}$ & $\begin{array}{l}\text { higher } \alpha-\mathrm{TOH} \text { plasma level in MetS } \\
\text { patients }\end{array}$ & - \\
\hline & Observational & Yen et al. [96] & $\begin{array}{l}n=72 \text { MetS patients } \\
n=105 \text { healthy controls }\end{array}$ & $\begin{array}{l}\alpha-\mathrm{TOH} / \mathrm{TG} \text { plasma level remained } \\
\text { unchanged }\end{array}$ & - \\
\hline & Interventional & Mah et al. [97] & $\begin{array}{l}n=10 \text { MetS patients } \\
n=10 \text { healthy controls }\end{array}$ & $\begin{array}{l}\text { MetS patients have lower } \alpha \text {-TOH /lipid } \\
\text { plasma level and lower } \alpha \text {-TOH absorption } \\
\text { and impaired hepatic trafficking compared } \\
\text { to healthy subjects }\end{array}$ & $15 \mathrm{mg} \alpha-\mathrm{TOH}$ once \\
\hline
\end{tabular}




\subsection{Hypertension}

Hypertension, defined as a systolic blood pressure (SBP) $\geq 130 \mathrm{mmHg}$ and/or a diastolic blood pressure $(\mathrm{DBP}) \geq 80 \mathrm{mmHg}$, is a major public health burden worldwide [98] and the most prevalent cause of CVD, but only about $50 \%$ of patients are adequately treated and achieve adequate blood pressure (BP) control.

An observational study by Kuwabara et al. [53] re-analyzed the data from the National Health and Nutrition Survey 2007 and studied the relationship between hypertension and dietary intake of vitamin E. In this study, data from 2102 females and 1405 males were analyzed. Higher vitamin E intake was associated with lower prevalence of hypertension. A recent meta-analysis including 839 participants in 18 clinical trials suggested that vitamin E supplements significantly decreased only SBP (15 clinical trials). However, vitamin E supplementation had no favorable effect on DBP (12 clinical trials) or mean arterial pressure (five clinical trials) [99]. Within this meta-analysis, the characteristics of the patients were very diverse. Vitamin E doses varied from 134 to $1206 \mathrm{mg}$ per day and the duration of supplementation varied between 3 and 48 weeks. Focusing on the hypertensive trials only, Boshtam et al. showed that vitamin E reduced blood pressure in mild hypertensive participants [54]. In a randomized, triple-blinded study, 70 mild hypertensive patients were allocated into a vitamin $\mathrm{E}$ supplement (134 mg per day (200 IU per day)) or a placebo group. After 27 weeks, vitamin E supplementation caused a remarkable decrease in SBP (-24\% versus $-1.6 \%$ in placebo) and a less remarkable decrease in DBP ( $-12.5 \%$ versus $-6.2 \%$ in placebo). A more recent study also demonstrated a decrease in blood pressure after 12 weeks of vitamin E supplementation (134 mg per day) in mild hypertensive subjects [55]. Palumbo et al. demonstrated in 142 treated hypertensive patients that 12 weeks of vitamin E supplementation (300 mg per day) showed no clinically relevant effect on blood pressure [56]. A further study by Mihalj et al. [57] also showed no further effect of vitamin E supplementation in patients treated with antihypertensive therapy, in this case an angiotensin II receptor blocker. Barbagallo et al. showed no effect of vitamin E treatment on SBP or DBP in 12 hypertensive patients treated with $600 \mathrm{mg}$ vitamin $\mathrm{E}$ per day for 4 weeks in comparison to a placebo control group [58]. The effect of vitamin E supplementation (500 $\mathrm{mg}$ per day for 6 weeks) on high blood pressure variability was studied by Hodgson et al., and they showed no significant alteration in the rate of blood pressure variation [100]. Often, vitamin E supplementation is studied in combination with vitamin C. Mellyana et al. [101] demonstrated that a combination of vitamin E and C supplementation improved blood pressure in pediatric idiopathic nephrotic syndrome patients.

Despite promising preclinical models and observational studies, antioxidant strategies for the treatment of hypertension in the clinic has not achieved the expected success [102]. The use of vitamin $\mathrm{E}$ and other antioxidants in the treatment of hypertension, including the antioxidant effects of antihypertensive drugs, is controversial [103,104]. More convincing effects were shown in participants with mild hypertension, while trials with treated hypertension or uncontrolled hypertension have not shown benefits of vitamin E supplementation. One reason for this could be the complexity of this condition, as hypertensive patients are remarkably diverse, ranging from the young and lean to the obese and elderly. In each of these phenotypes, the role of vitamin E, as well as other oxidants, might be different and therefore diluted within clinical trials that do not select appropriate patient groups [102]. Furthermore, the duration and the dosage of supplementation of $\alpha$-TOH vary and might be important factors in successful therapy. Finally, oxidative stress might not be the cause but, rather, the consequence of hypertension in humans [57].

In conclusion, promising preclinical and observational studies of vitamin E supplementation in hypertensive disease have not been broadly replicated in randomized controlled trials (RCT, Figure 2). However, in the subgroup of patients with mild hypertension, vitamin E supplementation seems to provide some benefits. 


\subsection{Hyperlipidemia}

Currently, the most central approach to reducing the number of cardiovascular events is the lowering of circulating LDL-C, based on clear evidence of LDL-C being a strong causal risk factor for CVD [105,106]. Statins are the backbone of the therapy for hyperlipidemic patients [107]. They inhibit the $\beta$-hydroxy- $\beta$-methylglutaryl-coenzyme-A (HMG-CoA) synthetase, with atorvastatin, simvastatin, pravastatin, and lovastatin being the most common statins in use. Statins are categorized by their LDL-C-lowering capacity, and high-, moderate-, and low-intensity statins lower LDL-C by $\geq 50 \%$, $30-49 \%$, and $<30 \%$, respectively [107]. There are controversial findings on statins lowering vitamin E concentration [108]. Whereas some studies showed a reduction due to the LDL-C-lowering effect of statins, others did not. In addition, the pleiotropic effects of statins show anti-inflammatory, antioxidative, and anti-thrombotic properties. Hypercholesterolemic patients with increased oxidative stress showed lower vitamin E plasma levels compared to healthy subjects, potentially counterbalancing the increased oxidative stress level [59]. As reported by Cangemi et al., treatment with atorvastatin (10 mg/d), for $3 \mathrm{~d}$ and $30 \mathrm{~d}$, in hypercholesterolemic patients, respectively, decreased oxidative stress, measured by urinary isoprostanes, and restored levels of vitamin E/cholesterol [59]. These findings were supported by Lui et al.'s study showing atorvastatin $(10 \mathrm{mg} / \mathrm{d}$ for 5 months $)$ increased circulating vitamin E/LDL-C in hypercholesterolemic patients; however, the urinary oxidative stress marker 8-OHdG remained unchanged under atorvastatin treatment [62]. Simvastatin (20-40 mg/d) administered for 8 weeks in hypercholesterolemic patients significantly increased the levels of lipid-corrected $\alpha$-TOH and $\gamma$-TOH [60]. These findings support the hypothesis that statins possess antioxidative properties so that fewer additional antioxidants are needed. Therefore, additional supplementation with antioxidants in statin-treated patients will most likely not result in further decrease in oxidative stress [109,110].

Furthermore, clinical findings suggested that there might be an interaction between statins and vitamin E, since the regression of coronary artery disease observed with a combined therapy of simvastatin and niacin was lost in combination with vitamin $\mathrm{E}$ [63]. Thus, the effects of vitamin $\mathrm{E}$ on statin bioavailability and decreased therapeutic efficiency were suggested, since vitamin $\mathrm{E}$ and statins share similar hepatic metabolic enzymes. In addition to CYP4F2, vitamin E is metabolized by CYP3A4, the same enzyme system used for hepatic xenobiotic metabolism of simvastatin and lovastatin. However, Leonard et al. reported that vitamin E supplementation did not alter cholesterol levels under statin therapy [63].

Other therapeutic approaches to lowering LDL-C include the drug ezetimibe and the lowering of the proprotein convertase subtilisin/kexin type 9 (PCSK9) by either antibodies or genetic means. PCSK9-targeted therapy lowers LDL-C to concentrations of $<15 \mathrm{mg} / \mathrm{dL}$ by targeting LDL-C receptors for lysosomal degradation, instead of allowing them to be recycled to the hepatocyte cell surface. Initially with the anti-PCSK9 antibody, there was concern that this aggressive LDL-C lowering might lead to steroid hormone and vitamin E deficiency. Vitamin E is transported in the circulation via LDL-C particles. Consequently, reduction of LDL-C was expected to decrease vitamin E levels in circulation. However, this assumption was not confirmed [111]. Vitamin E concentration in red blood cells and in plasma remained unaltered [61], although LDL-C decreased to $<40 \mathrm{mg} / \mathrm{dL}$ for $87 \%$ and even to $<15 \mathrm{mg} / \mathrm{dL}$ for $40 \%$ of patients treated with evolocumab, a clinically used anti-PCSK9 antibody [61,111].

Consequently, the outcomes of large clinical trials, indicating that there is no beneficial effect of vitamin E supplementation, need to be analyzed with caution, as concomitant use of statins may have reduced vitamin E's effectiveness [112].

In summary, lipid-lowering therapies do not decrease circulating vitamin $\mathrm{E}$, but the opposite. In addition to lipid-lowering, statins exert anti-inflammatory and antioxidative effects. Consequently, decreased vitamin E plasma levels in hypercholesterolemic patients with increased oxidative stress can be restored by statins. However, additional beneficial effects on the CVD risk of supplemented vitamin $\mathrm{E}$ in patients receiving lipid-lowering therapies have not been observed. Metabolic interactions of vitamin E and statins that affect statins' bioavailability cannot be excluded, and are of special importance in the therapeutic efficiency of statins (Figure 2). 


\subsection{Thrombosis}

Thrombosis is the formation of a blood clot within blood vessels, both venous and arterial, leading to a partial or complete blockage of the vessel. Here, we mainly discuss studies focusing on vitamin $\mathrm{E}$ and venous thrombosis, as arterial thrombosis is discussed in Section 3.2. Regular doses of vitamin E may reduce the risk of venous thromboembolism in women. Glynn et al. [64] reviewed data from 39,876 women aged 45 and older taking part in the Women's Health Study. Women were randomly allocated to take either a regular dose of vitamin E (600 IU) or a placebo on alternate days over a 10 -year period. The data indicated that, in general, women taking vitamin E were $21 \%$ less likely to suffer a venous thromboembolism. The study authors cautioned that more research is needed to confirm this link in the prevention of venous thromboembolism.

A large case-controlled study by Vuckovic and colleagues [65] included 2506 patients with venous thrombosis, 2506 partner controls, and 2684 random-digit-dialing (RDD) controls. Only 96 patients were supplemented with vitamin $\mathrm{E}$, while the other patients were supplemented with other vitamins or a multivitamin supplement. This showed that after extensive adjustments, vitamin E supplementation was no longer associated with a decreased venous thrombosis risk. However, this study lacks information about the duration and dose of vitamin E supplementation, so it is unknown whether vitamin E supplementation would decrease venous thrombotic risk in people with low vitamin $\mathrm{E}$ baseline levels.

Furthermore, the interaction of vitamin E and K may affect thrombosis. The metabolic pathways of vitamin $\mathrm{E}$ and $\mathrm{K}$ showed parallels e.g., side chain $\omega$-hydroxylation by Cytochrom P450 4F2 (CYP4F2) and the following $\beta$-oxidation. Further pregnane $X$ receptor (PXR) binds vitamin $E$ and vitamin $\mathrm{K}$ and activates genes involved in xenobiotic detoxification such as multiple drug resistance 1 (MDR1) and CYP3A4 [113-117]. In addition, PXR binds the vitamin K metabolite menaquinone-4. The PXR/menaquinone-4 complex regulates collagen formation and extracellular matrix in osteoblastic cells [118]. The active form of vitamin $\mathrm{K}$, as an important regulator for blood coagulation, is altered by excessive vitamin $\mathrm{E}$. Hence, vitamin $\mathrm{E}$ has been suggested for therapeutic use in patients with increased risk of thrombosis [113].

Furthermore, the interaction of vitamin E and K may affect thrombosis. The metabolic pathways of vitamin $\mathrm{E}$ and $\mathrm{K}$ overlap with each other, e.g., side chain $\omega$-hydroxylation by Cytochrom P450 4F2 (CYP4F2) and the consequent $\beta$-oxidation. Furthermore, pregnane $X$ receptor (PXR, also known as SXR) binds vitamin $\mathrm{E}$ and vitamin $\mathrm{K}$ and activates genes involved in xenobiotic detoxification such as multiple drug resistance 1 (MDR1) and CYP3A4 [113-117]. In addition, PXR binds the vitamin $\mathrm{K}$ metabolite menaquinone- 4 . The PXR/menaquinone- 4 complex regulates collagen formation and extracellular matrix in osteoblastic cells [118]. Therefore, vitamin K2 may serve as a critical factor regulating bone matrix formation. Vitamin E may bind to the same receptor, however, so far there is no indication that high-dose vitamin E supplementation causes adverse effects on bone homeostasis [119]. The active form of vitamin $\mathrm{K}$, as an important regulator for blood coagulation, is altered by excessive vitamin E. High-dose vitamin E supplementation increased PIVKA-II in adults not receiving oral anticoagulant therapy. An increase in proteins induced by vitamin K absence-factor II (PIVKA-II) is an indicator of a poor vitamin K status. In contrast, other measures of the vitamin K status e.g., plasma phylloquinone concentration and percentage of ucOC did not change significantly in response to the vitamin E supplementation [120]. The finding that the higher the vitamin E serum levels, the higher the risk of bleeding has been related to competitive metabolism of vitamin $\mathrm{E}$ and $\mathrm{K}$, and high doses of vitamin E may antagonize vitamin K [121]. Vitamin E has even been discussed for therapeutic use in patients with increased risk of thrombosis [113].

In summary, the number of studies focusing on the effect of vitamin E supplementation on thromboembolic risk is low, and to our knowledge there is no study directly reporting on vitamin E plasma levels and the associated risk of venous thromboembolism. As such, further studies are needed to answer the question of a potential risk reduction in venous thromboembolisms by vitamin $\mathrm{E}$ supplementation (Figure 2). 


\subsection{Chronic Inflammation}

\subsubsection{Age}

With increasing age, the burden of elevated oxidative stress promotes both infections and non-communicable diseases such as CVD, cancer, Alzheimer's disease (AD), and diabetes mellitus type 2 (DMT2). In short, aging is associated with chronic low-grade inflammation, which alters the health status of elderly subjects. Partly inadequate nutritional intake of macro- and micronutrients by the elderly confounds this finding. Elderly people living independently must also be distinguished from subjects living in aged-care or similar institutions [122]. Critical nutritional deficits were observed concerning antioxidant micronutrients, thus forcing an imbalance between enhanced oxidative processes during aging and levels of antioxidants. As reported in several studies, the plasma concentration of $\alpha-\mathrm{TOH}$ is decreased in older adults, associated with a higher incidence of infections such as upper respiratory infections [123], non-communicable diseases, and impairment of cognitive function [66]. Other studies have observed an inverse correlation of $\alpha$-TOH plasma level in patients with DMT2, but not in age-matched healthy subjects $[67,124]$. In contrast, the plasma concentration of $\gamma-\mathrm{TOH}$ and concentrations of $\alpha-\mathrm{TOH}$ and $\gamma-\mathrm{TOH}$ in platelets, as well as total tocopherol concentrations, decreased significantly with age [67]. However, the hypothesis cannot be completely excluded that lower nutritional intake of $\alpha$-TOH causes the observed deficiencies, rather than increased consumption of $\alpha$-TOH due to higher oxidative stress [68], although age-related differences in vitamin E metabolism were also suggested [125]. The majority of institutionalized elderly subjects have been reported to consume less than two-thirds of the recommended daily intake (RDI) of $\alpha$-TOH [69,70]. The current RDI level of vitamin $\mathrm{E}$ is $15 \mathrm{mg} / \mathrm{d}$ for subjects $>14$ years, regardless of varying circumstances during aging. The German Society of Nutrition recommends $11 \mathrm{mg} / \mathrm{d}$ for women and $12 \mathrm{mg} / \mathrm{d}$ for men $>65$ years. Therefore, Meydani and colleagues recently raised the question of whether the RDI of vitamin E should be adjusted, thus improving immune and inflammatory responses, and reducing the risk of age-related diseases [126,127], such as poor mental health [68]. A daily intake level of $200 \mathrm{IU}$ $\alpha$-TOH has proven to increase immunity, more precisely T-cell function, in elderly individuals [71,127].

In summary, several studies have reported critical antioxidant deficits in the elderly. As potential causes, a lower nutritional intake of $\alpha-\mathrm{TOH}$, mostly observed in institutionalized elderly subjects, and increased consumption of $\alpha-\mathrm{TOH}$, due to higher oxidative stress with increasing age, have been discussed. Comorbidities often contribute to a-TOH deficiency (Figure 2).

\subsubsection{Obesity}

Obesity is a global pandemic, with increasing incidences being most alarming in children and adolescents. Data from the US National Health and Nutrition Examination Survey (NHANES) showed that one-third of adults and 12.5 million children and adolescents in the United States are classified as obese. Over 1999-2018 prevalence of overall obesity increased from 30.5\% to $42.4 \%$ and severe obesity increased from $4.7 \%$ to $9.2 \%$ [128]. The consequences of this are dire, since obesity is an independent, strong risk factor for DMT2 and CVD. Obesity is accompanied by low-grade inflammation triggered by increased oxidative stress and lipid or protein oxidation [129,130]. Therefore, there is a clear need for an adequate supply of antioxidants, such as vitamin E. Studies reporting on the nutritional intake of vitamin $\mathrm{E}$ have found no differences in vitamin $\mathrm{E}$ intake in obese compared to non-obese subjects $[75,129]$ or increased $\alpha-\mathrm{TOH}$ intake due to the nature of vitamin $\mathrm{E}$ as a fat-soluble vitamin [72]. Intake of monounsaturated fatty acids (MUFA) and PUFA is increased in obese subjects, resulting in increased total cholesterol (TC), LDL-C and triglycerides (TG), and vitamin E intake, whereas high-density lipoprotein cholesterol (HDL-C) is decreased [129,130]. However, intake of vitamin E does not correlate with vitamin E plasma level [72]. Lipids, more precisely PUFA and MUFA, are prone to oxidation, which is prevented by $\alpha-\mathrm{TOH}$. As a result, $\alpha-\mathrm{TOH}$ plasma level is decreased in obese individuals due to the consumption of $\alpha-\mathrm{TOH}$, as shown in several studies [72-74,131]. In obese compared to non-obese children, age-matched controls from the NHANES survey of $\alpha$-TOH plasma 
level were $2.68 \pm 0.59$ vs. $3.17 \pm 0.60$ after the adjustment of TC and TG $(p<0.001)$ [75]. In contrast, other studies have reported plasma levels of $\alpha_{-}, \beta-, \gamma_{-}^{-}$, and $\delta-\mathrm{TOH}$ to be unchanged [76] or even increased $(\gamma-\mathrm{TOH})$ in obese subjects [132]. Furthermore, $\alpha-\mathrm{TOH}$ plasma level negatively correlates with waist circumference and waist-to-hip ratio [73], as well as body mass index (BMI), truncal fat mass, and total body fat mass [77]. A study by Verrotti et al. showed that epileptic girls treated with valproic acid for one year who became overweight had decreased $\alpha-\mathrm{TOH}$ plasma levels, compared to baseline level or normal-weight adolescents [133]. The discontinuation of this drug [133] and weight loss [134] reversed obesity, and subsequently normalized antioxidant plasma levels. Adequate plasma concentrations of $\alpha-\mathrm{TOH}$ are associated with reduced probability of overweight (OR: $0.56 ; 95 \%$ CI: $0.37,0.86 ; p<0.05$ ) and obesity (OR: $0.38 ; 95 \%$ CI: $0.24,0.60 ; p<0.01)$ [77] and it is therefore important to prevent oxidative stress as an early event in the pathogenesis of complications such as DMT2 and CVD.

In summary, a large body of evidence shows that obesity is accompanied by increased oxidative stress resulting in low-grade inflammation. In obesity, the intake of fat and therefore of vitamin $\mathrm{E}$ is usually increased. Nevertheless, vitamin E plasma level is decreased in obese subjects, since vitamin E protects lipids from oxidation, and is therefore increasingly consumed. Consequently, obesity increases the risk of CVD and cardiovascular events. To offset the observed reduction in vitamin $\mathrm{E}$ level, supplementation of vitamin $\mathrm{E}$ in obese subjects seems to be a well-justified consideration. However, there is no evidence for this from any RCT (Figure 2).

\subsubsection{Diabetes Mellitus Type 2}

Diabetes mellitus type 2 is the non-insulin-dependent form of diabetes mellitus, and is characterized by impaired function of pancreatic $\beta$-cells, resulting in insufficient insulin production, insulin resistance, and an increased plasma glucose level. An increased glucose plasma level correlates with increased oxidative stress and decreased vitamin E plasma concentration, possibly due to elevated phospholipid transfer protein (PLTP) level and activity [78]. PLTP transfers $\alpha$-TOH from apolipoprotein B-containing lipoproteins to HDL-C or cellular membranes. Consequently, in patients with DMT2 and elevated plasma PLTP concentrations, vitamin E content in VLDL and LDL-C is reduced, which likely results in increased susceptibility of LDL-C to being oxidized and changes in vitamin E distribution [78]. Furthermore, Galvan et al. showed that insulin infusion decreased the vitamin E/LDL-C ratio by $10.0 \pm 1.2 \%$ compared to saline infusion $(p<0.002)$, which suggests that insulin acts as a pro-oxidant agent, consuming vitamin $\mathrm{E}$ to buffer insulin-induced production of hydrogen peroxide [79]. The $\alpha-\mathrm{TOH}$ and $\gamma-\mathrm{TOH}$ [135]-binding protein afamin in extravascular fluids or tissues was reported to be an independent predictor for the incidence of DMT2 in a meta-analysis of eight prospective cohort studies, with a total of 20,136 subjects [80]. An increase in afamin by $10 \mathrm{mg} / \mathrm{L}$ was associated with prevalent DMT2 diabetes (OR 1.19, 95\% CI 1.12, 1.26) [80], whereas the association of afamin and vitamin E plasma level is still under debate.

Oxidative stress is accompanied by consumption of $\alpha-\mathrm{TOH}$; thus, the Insulin Resistance and Atherosclerosis Study (IRAS) found an inverse correlation between plasma $\alpha-\mathrm{TOH}$ and diabetes incidence (OR $0.12,95 \%$ CI $0.02,0.68 ; p<0.01$ ) [81]. Diabetic patients with macroangiopathy had significantly lower $\alpha-\mathrm{TOH}$ concentrations compared to those without vascular changes $(p<0.05)$, measured by $\mathrm{N}$-acetyl-h-glucosaminidase activity and endothelial dysfunction [82]. Indeed, a $1 \mu \mathrm{mol} / \mathrm{L}$ decrease in plasma $\alpha$-TOH levels was reported to increase diabetes risk by $22 \%(p=0.0004)$ [136]. Individuals in the IRAS developing DMT2 had significantly lower $\alpha$-TOH baseline levels compared to controls $(25.1 \pm 7.5 \mu \mathrm{mol} / \mathrm{L}$ vs. $28.1 \pm 8.8 \mu \mathrm{mol} / \mathrm{L} ; p<0.01)$ [81]. Overall, reported differences in $\alpha-\mathrm{TOH}$ plasma concentration are in the range of $28 \%$ [84] to $35 \%$ [85]. However, no correlation of nutritional vitamin $\mathrm{E}$ intake with incidence of diabetes was found [81].

Supplementation of 800 IU vitamin E per day for 4 weeks decreased the susceptibility of LDL-C to being oxidized [137]. Furthermore, $\alpha-\mathrm{TOH}$ supplementation significantly decreased inflammatory level, measured by the levels of C-reactive protein (CRP) and IL-6, in patients with DMT2 compared to matched controls [138]. Combined supplementation of vitamin E (300 IU per day) and vitamin 
C (267 mg per day) for 3 months showed decreased blood glucose level and antioxidative capacity, measured by increased SOD and GSH enzyme activity, which lowered oxidative stress and consequently insulin resistance [86].

Obesity expedites insulin resistance, which, in the long term, results in impaired glucose tolerance, increased oxidative stress, and DMT2 [129]. In addition, absolute body fat content is inversely correlated with antioxidative status and $\alpha-\mathrm{TOH}$ concentration, which itself inversely correlates with fasting plasma insulin concentration and the Homeostatic Model Assessment of Insulin Resistance (HOMA-IR) index [76]. A 3-month supplementation with $800 \mathrm{IU}$ vitamin E per day in overweight individuals decreased fasting plasma glucose and improved insulin sensitivity, possibly independent of changes in inflammatory processes, which seemed not to be apparent after 6 months [87]. Other studies reported no correlation of increased insulin resistance in obesity with vitamin E concentration [73]. However, a meta-analysis of 14 RCTs involving 714 subjects revealed that vitamin E supplementation did not result in significant benefits to glycemic control as measured by reductions in hemoglobin $\mathrm{A}_{1 \mathrm{c}}\left(\mathrm{Hb}_{1 \mathrm{c}}\right)$, fasting glucose, and fasting insulin [88].

In conclusion, clinical trials show increased oxidative stress in patients suffering DMT2, which results in decreased vitamin E plasma levels. In addition, lower plasma $\alpha$-TOH levels are correlated with an increased risk of development of diabetes. To the best of our knowledge, no study exists showing a correlation between nutritional vitamin $\mathrm{E}$ intake and the risk of developing diabetes. Although supplementation of vitamin E decreases oxidative stress and insulin resistance, insufficient evidence currently exists to support a potential beneficial effect of vitamin E supplementation in subjects with DMT2 [81] and related increased risk of CVD accompanying the progression and duration of the disease (Figure 2).

\subsubsection{Fatty Liver Disease}

Non-alcoholic fatty liver disease (NAFLD) is globally the most common chronic liver disease [139], and often remains undiagnosed until a certain stage of the disease. Non-alcoholic fatty liver disease is a combination of inflammation, oxidative stress, and excessive accumulation of lipids in the liver. Inflammation in NAFLD is most likely accelerated by alteration of the gut microbial populations [140,141], and is hallmarked by activation of central inflammatory pathways such as NF- $\mathrm{kB}$, signal transducer and activator of transcription (STAT)-3, and the inflammasome, resulting in increased production of pro-inflammatory cytokines. Similar findings have been reported for atherosclerosis and CVD $[142,143]$. During its development, several stages and severities of NAFLD can be defined [144], positively correlated with both the prevalence and the incidence of CVD [145]. Patients with non-alcoholic steatohepatitis (NASH), an advanced stage of fatty liver disease, appear to be at greater risk of CVD [145]. Since fatty liver disease and CVD share similar risk factors, such as DMT2, obesity, dyslipidemia, and hypertension, medications used to treat comorbidities are currently being used or tested for the therapy of NAFLD/NASH [146]. Dependent on the magnitude of the disease, lifestyle management and treatment with peroxisome proliferator-activated receptors (PPAR), $\gamma$ agonists and vitamin $\mathrm{E}$, more precisely $\alpha-\mathrm{TOH}$, have been shown to be effective therapeutic strategies. Fatty liver disease is an inflammatory disease, and thus elevated oxidative stress levels decreased $\alpha$-TOH plasma levels in NASH patients compared to healthy subjects $(22.4 \mathrm{vs} .26 .8 \mathrm{nmol} / \mathrm{mL} ; p<0.01)$, whereas $\gamma$-TOH remained unchanged [89]. This observation supports the hypothesis that $\alpha-\mathrm{TOH}$ is the most active antioxidative form of vitamin E. A recent study of Violet et al. showed alteration of $\alpha$-TOH kinetics in women with obesity-associated hepatosteatosis compared to healthy controls, resulting in decreased release of $\alpha-\mathrm{TOH}$ from the liver, consequently lowering the concentration of circulating $\alpha-\mathrm{TOH}$ [91]. In addition, the authors postulate complex-like binding of $\alpha-\mathrm{TOH}$ to lipids, which in the following avert $\alpha$-TOH ROS-quenching properties and thus causing a worsening of the disease [91].

In contrast, other studies found increased $\alpha-\mathrm{TOH}$ plasma levels in NASH patients $(47.1 \mu \mathrm{M}$ vs. $34.5 \mu \mathrm{M} ; p<0.001$; NASH vs. control) [90]. Nevertheless, vitamin E treatment was found to be one of the few established therapies for NAFLD and NASH, as shown in the Pioglitazone versus Vitamin E 
versus Placebo for the Treatment of Nondiabetic Patients with Nonalcoholic Steatohepatitis (PIVENS) study [92]. In this study, a two-year intervention with $800 \mathrm{IU} / \mathrm{d} \alpha-\mathrm{TOH}$ in non-diabetic patients with biopsy-diagnosed NAFLD significantly reduced the primary outcome (steatohepatitis) compared to placebo (43\% vs. $19 \% ; p=0.001)$. $\alpha$-Tocopherol plasma level was significantly associated with the genotype V433M of CYP4F2, the cytochrome that predominantly metabolizes vitamin $\mathrm{E}$ in the liver, as well as resolution of NASH and overall histological improvement [125]. However, these findings could not be replicated in the Treatment of Nonalcoholic Fatty Liver Disease in Children (TONIC) study in children diagnosed with obesity-induced NASH receiving 400 to $1200 \mathrm{IU} \alpha$-TOH for up to 10 months [93] (Figure 2). Consequently, the relationship between CYP4F2 polymorphisms and the pharmacological effectiveness of vitamin E seems to be complicated by age differences [125].

In summary, inflammatory fatty liver disease is characterized by elevated oxidative stress resulting in decreased $\alpha$-TOH plasma level and is also correlated with CVD. $\alpha$-Tocopherol has been approved as an effective therapeutic strategy. However, polymorphisms of the hepatic vitamin E-metabolizing cytochrome are suggested to affect the pharmacological effectiveness of vitamin E supplementation.

\subsubsection{Metabolic Syndrome}

Metabolic syndrome (MetS) typically combines five or more of the following metabolic disorders, namely, hyperlipidemia, hyperglycemia, hypertension, abdominal obesity, and insulin resistance $[95,146]$. Notably, each of these factors represents an increased risk for DMT2, NAFLD, and CVD, and thus, subjects suffering from one or more of these metabolic disorders possess an increased risk of developing these sequelae. Metabolic syndrome is characterized by increased oxidative stress and radical formation [95], consequently requiring a higher intake of antioxidants to avoid an imbalance between antioxidant levels and oxidative processes [97]. In addition, the bioavailability of vitamin E, more precisely $\alpha-\mathrm{TOH}$, was decreased in MetS patients compared to healthy subjects $(12 \% ; p<0.05)$, possibly due to limited small-intestinal $\alpha$-TOH absorption and/or impairment of hepatic $\alpha$-TOH trafficking [97]. In fact, $\alpha$-TOH plasma $(18 \%, p=0.042)[94,147]$ and organ level [148], as well as $\alpha$-CEHC excretion level $(41 \%, p=0.002)$ [149], a biomarker for $\alpha$-TOH status, are significantly lower in patients with MetS compared to non-MetS patients. Some studies show that $\alpha$-TOH uptake and plasma levels are significantly higher in MetS patients [95]. However, there were no adjustments for lipid, cholesterol, or triglyceride uptake or plasma concentration of $\alpha-\mathrm{TOH}$, respectively [95,96]. Currently, an increased requirement for $\alpha-\mathrm{TOH}$ in patients suffering from MetS is postulated, but not proven [97]. Indeed, a cohort of NHANES over 2001-2006 conducted in adults aged 20-85 years showed an inverse correlation between serum antioxidant status and MetS [95]. Although supplementation with $\alpha-\mathrm{TOH}$ in rats reversed most of the metabolic disorders of MetS [150], no benefit of supplementation with $\alpha-\mathrm{TOH}$ in a generally well-nourished population was observed, which is consistent with the outcomes for other diseases characterized by increased oxidative stress [151].

MetS combines several clinical characteristics associated with increased oxidative stress, resulting in an imbalance between antioxidant levels and oxidative processes. However, there is currently no intervention study in humans reporting beneficial effects of supplementation with $\alpha-\mathrm{TOH}$ in a generally well-nourished population on the incidence of MetS and consequently CVD or cardiovascular events (Figure 2).

\subsection{Cardiovascular Events, Particularly MI}

An early study by Gey et al. [152] found a strong inverse association between plasma vitamin E level and IHD mortality. Furthermore, the risk of angina pectoris was inversely associated with the plasma concentration of vitamin $\mathrm{E}$ in a case-controlled population study of 110 cases of angina, even after adjustment for age, smoking habit, blood pressure, lipids, and relative weight [153].

Recently, Huang et al. reported in a long-term prospective cohort study, including biochemical analysis of 29,092 participants, that higher baseline serum $\alpha$-tocopherol was associated with lower risk of overall mortality and mortality from all major causes. This study supports the long-term health benefits of higher serum $\alpha$-TOH for overall and disease-specific mortality such as CVD [154]. 
Several observational studies [155-162] have consistently shown that vitamin E supplementation and/or high vitamin E intake is associated with a decreased risk of CVD. To our knowledge, only one Mendelian randomization study in China showed that high vitamin E levels were associated with an increased risk of CVD [163]. Despite this study, the overall consistency in the other studies has led many to suggest that vitamin E supplements may reduce the risk of CVD and several interventional trials have begun to study the cardioprotective effect of vitamin $\mathrm{E}$.

Most studies have focused on vitamin E and the risk of CVD in general, while only a few have looked at the risk of major single causes of CVD like MI. A recent study from China stated that high vitamin E levels could increase the risk of MI [163]. A prospective study by Hak et al. [164] also reported that men without a history of CVD and with higher plasma vitamin $\mathrm{E}$ tended to have an increased MI risk. Hense and colleagues [165] found no association between serum vitamin E concentration and MI risk in their study population; however, they suggested that this might have been due to the high average levels of vitamin $\mathrm{E}$ in their study population.

A high plasma level may not be associated with a lower risk of MI; nevertheless, an interesting observation is a decrease in vitamin E plasma level in MI patients [166]. Within the first $48 \mathrm{~h}$ after MI, the plasma level of vitamin E declines significantly by $26 \%$ [167], and remains low until the third day after the start of the catabolic response [168]. Following an infarct, Sood et al. [169] showed that reperfusion was associated with excessive oxidative stress and increased consumption of this antioxidant not only in the ischemic but also in the reperfused myocardium. Vitamin E can be suggested as a valid marker for reperfusion and supplementation of vitamin E could be a therapeutic option for antioxidative protection of the myocardium in the acute setting.

Overall, numerous observational studies have consistently reported that high vitamin $E$ intake or supplementation is associated with a decreased risk of CVD and overall mortality. However, no interventional trial in humans has shown, so far, the benefit of a supplementation of vitamin $\mathrm{E}$ to prevent any cardiovascular event. The decrease in vitamin E plasma level within the first $48 \mathrm{~h}$ after MI and the high demand for vitamin $\mathrm{E}$ during reperfusion might be promising therapeutic indications for short-term vitamin E supplementation.

\section{Effects of Vitamin E in Chronic vs. Acute Events}

The correlation of plasma level and supplementation of vitamin $\mathrm{E}$ with the incidence of cardiovascular events will be discussed in detail in the following chapter, and is summarized in Figure 3.

\begin{tabular}{|c|c|c|c|c|c|}
\hline \multicolumn{6}{|c|}{ Cardiovascular events and vitamin E } \\
\hline \multicolumn{4}{|c|}{$\downarrow$} & \multicolumn{2}{|l|}{$\downarrow$} \\
\hline \multicolumn{4}{|c|}{ Chronic disease } & \multicolumn{2}{|l|}{ Acute disease } \\
\hline$\downarrow$ & & \multicolumn{2}{|l|}{$\downarrow$} & \multicolumn{2}{|l|}{$\downarrow$} \\
\hline \multicolumn{2}{|l|}{ CAD } & \multicolumn{2}{|c|}{ Atherosclerosis } & \multicolumn{2}{|l|}{ MI } \\
\hline Observational & 仓 & Preclinical & 仓 & Observational & 仓 \\
\hline \multirow[t]{4}{*}{ Interventional } & 仓田 & Interventional & 仓 & Chronic supplementation: Primary prevention & $\sqrt{t}$ \\
\hline & & & & Chronic supplementation: Secondary prevention & 个四 \\
\hline & & & & Acute treatment: Preclinical & $\hat{\mathrm{U}}$ \\
\hline & & & & Acute treatment: Interventional & (b) \\
\hline
\end{tabular}

Figure 3. Correlation of plasma level and supplementation of vitamin E with incidence of cardiovascular events. Relevance of vitamin E to the risk of cardiovascular diseases (CVD) depends on the inflammation grade resulting from chronic and acute cardiovascular events. Increased vitamin E plasma levels correlate with decreased risk of chronic CVD, ischemic heart disease (IHD), and atherosclerosis, whereas supplementation of vitamin $\mathrm{E}$ has revealed controversial results. In acute cardiovascular events, such as myocardial infarction (MI), acute treatment of vitamin $\mathrm{E}$ is most promising in balancing a deficiency of antioxidants. Abbreviations used in the figure: vitamin E, VE. 


\subsection{Atherosclerosis/Plaque Formation/Stability and Primary/Secondary Prevention}

Several preclinical studies have demonstrated a preventive effect of vitamin $\mathrm{E}$ in plaque formation, such as preventing foam cell formation and endothelial dysfunction [170], scavenging free radicals in vascular SMC, preventing oxidative modification of LDL-C [171], reducing vascular SMC proliferation by protein kinase C [172-176], modulating endothelial cells [177], preventing the expression of adhesion molecules on endothelial cells [178,179] and mononuclear cell infiltration [180], adhering monocytes to endothelium [181], and curtailing the destabilization of fibrous plaques [182]. Furthermore, Schwenke and colleagues [183] showed, in rabbits fed with high doses of $\alpha$-tocopherol, compared to low doses, significantly lower total plasma cholesterol and a decrease in atherosclerosis.

Despite these strong preclinical data on vitamin E's effects on atherogenesis, clinical data has not supported these findings. Vitamin E supplementation does not attenuate plaque formation. The Vitamin E Atherosclerosis Prevention Study (VEAPS) [184] reported that, in healthy individuals at low risk of CVD, vitamin E supplementation did reduce LDL oxidation, but had no noticeable effect on the progression of atherosclerosis measured by carotid intima-media thickness (IMT). The Perth Carotid Ultrasound Disease Assessment Study (CUDAS) [185] demonstrated a progressive decrease in mean IMT with increasing quartiles of dietary vitamin E intake in men $(p=0.02)$ and a non-significant trend in women $(p=0.10)$. The Melbourne Atherosclerosis Vitamin E Trial (MAVET) [186] reported that vitamin E supplementation in chronic smokers failed to reduce the progression of carotid atherosclerosis. Furthermore, the Antioxidant Supplementation in Atherosclerosis Prevention (ASAP) trial, which combined vitamin E and C supplementation in hypercholesterolemic subjects [83], a randomized, controlled, double-blind trial, including 90 patients with coronary artery disease [187], and the Study to Evaluate Carotid Ultrasound Changes in Patients Treated with Ramipril and Vitamin E (SECURE) [188], did not observe differences in the progression of atherosclerosis between patients with vitamin E supplementation and placebo.

Overall, the preventive effects of vitamin $\mathrm{E}$ alone or in combination with vitamin $\mathrm{C}$ seen in preclinical models of atherosclerosis have not been confirmed in clinical trials. Long-term supplementation of vitamin E does not seem to attenuate atherogenesis in humans (Figure 3).

\subsection{Myocardial Infarction}

Most studies have focused on the benefits of vitamin E supplementation in CVD, as reported above in Section 4.5. However, a few primary and secondary prevention trials have looked more specifically into whether vitamin E supplementation can reduce the incidence of fatal or non-fatal MI.

First, the primary prevention of angina pectoris by $\alpha$-TOH supplementation in healthy smokers aged 50-69 years was studied in the Finnish Alpha-Tocopherol Beta Carotene (ATBC) study [189]. $\alpha$-Tocopherol supplementation was associated with only a minor decrease in the incidence of angina pectoris. A further study, the Collaborative Primary Prevention Project (PPP) [190], investigated the efficacy of vitamin E ( $\alpha$-tocopherol) in primary prevention of cardiovascular events in people with one or more major cardiovascular risk factor. Vitamin E supplementation showed no effect on CVD death, total cardiovascular events, or MI. Thus, long-term, high-dose vitamin E supplementation fails to prevent MI.

Several trials were performed investigating secondary prevention of cardiovascular events by vitamin E supplementation in patients with clinical evidence of CVD. In the Cambridge Heart Antioxidant Study (CHAOS) [191], supplementation with vitamin E substantially reduced the incidence of non-fatal MI after 1 year of treatment. A further study, the Secondary Prevention with Antioxidants of Cardiovascular Disease in Endstage Renal Disease (SPACE) trial [192], reported a significant decrease in acute $\mathrm{MI}$ in hemodialyzed patients with vitamin E supplementation. However, a further large prospective trial, the Gruppo Italiano per lo Studio della Supervienza nell'Infarto miocardico (GISSI), including 11,324 subjects with a recent MI, showed no effect of vitamin E treatment on non-fatal MI [193]. Notably in this study, all subjects were invited to follow a Mediterranean diet, which may have led to a high vitamin E food intake in all study groups. Furthermore, a meta-analysis of nine 
studies with 80,645 participants reported an association between vitamin E supplementation and a reduction in non-fatal MI in patients with pre-existing coronary artery disease, but no association with a reduction in total mortality or total CVD mortality [194].

The secondary prevention of MI with vitamin E supplementation is controversial and might be a question of treatment strategy and patient profiling. Moreover, the presented trials have tested vitamin E's capacity to provide plaque stabilization, reduce the risk of plaque rupture, or prevent cardiovascular events like MI, but not the potential of vitamin E in preserving cardiac function in the event of acute MI. There are only limited data addressing this question. Nevertheless, the preclinical studies available show potential benefits of vitamin $\mathrm{E}$ in models of ischemia/reperfusion injury in various organs, including a few early studies on cardiac ischemia/reperfusion injury [195-198]. The first clinical trials have also shown promising results. The Myocardial Infarction and VITamins (MIVIT) trial [199] showed in a pilot trial including 800 patients a positive influence on the clinical outcome for patients with acute MI, as well as the Indian Experiment on Infarct Survival-3 [200]. This study suggested that combined treatment with antioxidant vitamins $A, E, C$, and $\beta$-carotene in patients with recent acute $\mathrm{MI}$ improved clinical outcomes and may have been protective against cardiac necrosis and oxidative stress. To our knowledge, there are only a few pilot studies looking at cardioprotection in the acute setting of MI, and in these trials, vitamin E supplementation is combined with other antioxidants. The effect of vitamin E supplementation alone on infarct size and preservation of cardiac function in MI patients has not been investigated so far. Therefore, clinical studies are warranted to investigate the potential of vitamin E medication in the acute setting of MI.

In summary, primary and secondary prevention of MI with vitamin E supplementation has largely failed to prevent MI. Vitamin E treatment directly in patients presenting with MI with the aim of preventing acute cardiac ischemia/reperfusion injury might be a promising vitamin $\mathrm{E}$ medication strategy where further clinical trials are warranted (Figure 3).

\section{Controversial Outcome of RCTs-Explanatory Approaches}

As reported earlier, studies investigating vitamin E's potential to reduce cardiovascular events have failed to show consistent results [201]. The potential reasons for this are diverse but important to understand. The potential impacts of proteins regulating vitamin E homeostasis [202], different doses and durations of vitamin E supplementation, as well as the specific vitamin E form applied, have been widely discussed. Furthermore, interactions of the different vitamin $E$ forms with each other or with co-treated medications must also be taken into consideration (Figure 4).

\begin{tabular}{|c|c|c|c|c|c|}
\hline \multicolumn{6}{|c|}{ Critical parameters in RCTs } \\
\hline Cohort Collection & Vitamin E forms & Duration & Doses & Metabolism & $\begin{array}{l}\text { Synergism } \\
\text { Antagonism }\end{array}$ \\
\hline $\begin{array}{l}\text { - Genetic } \\
\text { predisposition } \\
\text { - Acute } \\
\text { inflammation } \\
\text { - Low-grade } \\
\text { inflammation }\end{array}$ & $\begin{array}{ll}\text { - } & \alpha-\mathrm{TOH} \\
\text { - } & \text { Non- } \alpha-\mathrm{TOH} \\
\text { - } & \text { Combination of } \\
& \text { vitamin E forms }\end{array}$ & $\begin{array}{ll}\text { - } & \text { Long-term } \\
\text { intervention } \\
\text { - } & \text { Short-term } \\
\text { intervention }\end{array}$ & $\begin{array}{l}\text { - Offsetting } \\
\text { deficiency } \\
\text { - High-dose } \\
\text { supplementation } \\
\text { of adequately } \\
\text { supplied subjects }\end{array}$ & $\begin{array}{l}\text { - Effects of } \\
\text { metabolites } \\
\text { - Individual } \\
\text { metabolism } \\
\text { efficiency }\end{array}$ & $\begin{array}{l}\text { Interaction of } \\
\text { Vitamin E: } \\
\text { - With other forms } \\
\text { - Medications } \\
\text { - Other nutrients }\end{array}$ \\
\hline
\end{tabular}

Figure 4. Critical parameters in randomized controlled trials (RCTs) investigating beneficial effects of vitamin E supplementation on CVD. Vitamin E is the most prominent lipid-soluble antioxidant additionally possessing anti-inflammatory capacity. However, in randomized controlled trials (RCTs) supplementation of vitamin $\mathrm{E}$ has revealed controversial effects on the risk of cardiovascular events. The reasons for these findings are diverse. The most common reasons discussed are: cohort selection, the form of vitamin E used for treatment and the treatment durations and doses of vitamin E, the relevance of hepatically formed metabolites, and the synergistic or antagonistic effects of different vitamin $\mathrm{E}$ forms on each other or on nutritional factors and medications. 


\section{1. $\alpha$-TOH vs Non- $\alpha$-TOH Forms}

In interventional studies, $\alpha-\mathrm{TOH}$ is the most common form used to investigate the cardiovascular effects of vitamin $\mathrm{E}$, due to its known anti-inflammatory effects, in addition to its property as an antioxidant. However, whether $\alpha-\mathrm{TOH}$ is effective when given without other vitamin $\mathrm{E}$ forms is not clear. In observational studies, the possible beneficial effects of non- $\alpha$-TOH forms, namely $\beta-, \gamma^{-}$, $\delta$-TOH and $\alpha-, \beta-, \gamma-, \delta-\mathrm{T} 3$, cannot be separated from those of $\alpha-\mathrm{TOH}$.

After $\alpha$-TOH, $\gamma-\mathrm{TOH}$ and $\gamma-\mathrm{T} 3$ are the next most interesting forms of vitamin $\mathrm{E}$, due to their potent antioxidative and anti-inflammatory capacity. Notably, $\gamma-\mathrm{TOH}$ is the only form of vitamin $\mathrm{E}$ characterized by an unsubstituted C-5 position, thus enabling electrophile trapping, which results in the detoxification of $\mathrm{NO}_{2}$ and peroxynitrite via the formation of 5-nitro- $\gamma$ - $\mathrm{TOH}$ [203]. Supplementation with $\gamma$-TOH-rich mixed TOHs showed enhanced inhibition of inflammatory status, as assessed by decreased plasma levels of pro-inflammatory markers, such as CRP, IL-6 [204-206], and F2-isoprostane, and reduced leukotriene $B_{4}$ from stimulated neutrophils [207,208]. As reviewed by Mathur et al., supplementation with $\gamma$-TOH affected markers of atherosclerosis in humans by attenuating oxidative and nitrosative stress via improvement of vascular endothelial function and lipid peroxidation, as well as coagulation and platelet aggregation [209].

The anti-inflammatory properties of non- $\alpha$-TOH forms, particularly T3, indicate beneficial effects in the prevention and therapy of chronic diseases [210]. Qureshi and colleagues are the pioneers in T3 research, describing protective effects in relation to risk factors for the progression of atherosclerosis and CVD in hypercholesterolemic humans, such as the lowering of serum cholesterol [211,212]. These findings were supported by a study by Yuen et al., showing significant decreases in total cholesterol and LDL-C plasma concentrations after 5 months of supplementation with $300 \mathrm{mg}$ per day mixed T3s [213]. Furthermore, the administration of T3 at 100 and $200 \mathrm{mg}$ per day for 2 months improved arterial compliance in healthy men [214]. However, large-scale human trials investigating the cardioprotective effects of non- $\alpha-\mathrm{TOH}$ forms are still to be performed.

It must be considered that the occurrence of $\mathrm{T} 3$ is rare and its bioavailability in humans is less than $1 \%$ compared to $\alpha-\mathrm{TOH}$, and thus, an increase in nutritional T3 is not automatically associated with a significant increase in circulation. In addition, non- $\alpha-\mathrm{TOH}$ forms are typically rapidly metabolized. Consequently, plasma concentrations of the non- $\alpha-\mathrm{TOH}$ forms are decreased and respective metabolites can be formed. Therefore, the beneficial effects of non- $\alpha$-TOH forms on atherosclerosis and related cardiovascular events may be missed. Furthermore, these metabolites independently mediate anti-inflammatory and antioxidative properties [210].

In summary, the different strengths of the antioxidative and anti-inflammatory properties of non- $\alpha$-TOH forms of vitamin E compared to $\alpha-\mathrm{TOH}$ are known. Based on the current state of research, $\gamma$-TOH and T3, as well as hepatically formed metabolites of $\alpha$ - and $\gamma$-TOH, are promising forms of vitamin $\mathrm{E}$ in the prevention of diseases driven by acute inflammatory and oxidative processes such as MI. To verify this, large-scale clinical trials are needed.

\subsection{Relevance of Metabolites}

Within the hepatically formed metabolites of vitamin E, SCMs as metabolic end-products were first described in relation to anti-proliferative and anti-inflammatory properties in cancer and immune cells, respectively [215]. In addition, the LCM of vitamin E, which are the first hepatic products formed during the metabolism of vitamin E, are described to make valuable contributions to the biological activity of vitamin E. Long-chain metabolites and their precursors, tocopherols and tocotrienols, differ only in the terminal oxidation of the side-chain, and thus, similar modes of action can be assumed. Birringer et al. allocated the substructures of different forms and metabolites of vitamin $\mathrm{E}$ to specific functional moieties, assigning the LCM, with a terminal hydroxyl and carboxyl group at the side-chain, as structures with higher anti-inflammatory activity than their parent chromanols and chromenols [216]. Indeed, research on these metabolites has revealed the effects of LCM on inflammatory processes [217-220] and lipid metabolism [221,222], thus providing evidence of their physiological relevance [215]. A recent study 
by our group investigating the effect of $\delta-\mathrm{T} 3-13^{\prime}-\mathrm{COOH}$ on the progression of atherosclerosis showed protective effects on intra-plaque inflammation, as measured by nitrotyrosine [219]. Furthermore, direct and indirect effects of LCM on the inflammasome NLRP3, which has been reported to play a key role in the development of atherosclerosis, have been discussed [144]. However, no effect on the formation of atherosclerotic plaques in high-fat diet fed Apoe ${ }^{-/}$mice was observed [219]. Data available on the mode of action of LCM revealed that $13^{\prime}-\mathrm{OH}$ and $13^{\prime}-\mathrm{COOH}$, at least in part, mediated different pathways in immune cells, as known from $\alpha-\mathrm{TOH}$, and mediated the observed effects in lower concentrations, as observed for $\alpha$-TOH. Taking this into account, the effects of vitamin $\mathrm{E}$ seem to be complicated by the circulating hepatically formed LCM of vitamin E [223]. Therefore, we are confident that LCM need to be considered in evaluation of the role of vitamin E in CVD, and as potential leading structures for drug development for the treatment of CVD as well as NAFLD/NASH [144].

The biological mode of action of the LCM and their relevance in human trials need to be investigated further. To date, RCTs investigating the effects of LCM on atherosclerosis and the cardiovascular event rate are lacking.

\subsection{Comparison of Vitamin E and Anti-Inflammatory Therapies}

Different forms of vitamin $\mathrm{E}$ are beneficial agents in protecting against oxidative and inflammatory stress. However, the effects reported in human trials are rather inconsistent, as shown for $\alpha$-TOH, or large-scale human trials are missing, as described for non- $\alpha$-TOH forms, making it difficult to reach a conclusion on the beneficial effects of vitamin $\mathrm{E}$ in primary and secondary prevention of cardiovascular events.

In contrast, recent large-scale clinical trials using highly specific anti-inflammatory therapies, such as an IL-1 $\beta$-neutralizing antibody, methotrexate, or colchicine, have revealed, at least in part, a reduction in cardiovascular events, thus, notably confirming the major contribution of inflammation to CVD, specifically atherosclerosis. Among the central therapeutic targets are pro-inflammatory cytokines, with a special focus on IL-1 $\beta$. Interleukin- $1 \beta$ is mainly activated by the inflammasome nucleotide-binding domain and leucine-rich repeat pyrin domain (NLRP) 3, which has been shown to play a major role in atherosclerosis and CVD [224]. A recent review showed a blocking effect of vitamin E on the priming and activation process of the NLRP3 inflammasome and the related formation of IL-1 $\beta$ [144].

In the Canakinumab Antiinflammatory Thrombosis Outcome Study (CANTOS), patients with elevated CRP level $\geq 2 \mathrm{mg} / \mathrm{L}$ were randomized in four groups receiving none, $50 \mathrm{mg}$, $150 \mathrm{mg}$, and $300 \mathrm{mg}$ IL-1 $\beta$ neutralizing antibody every 3 months. Targeting IL-1 $\beta$ revealed a decrease in CRP concentration of $26 \%$ to $41 \%$ after 4 years of treatment without affecting the plasma lipid profile [225]. Elevated CRP plasma levels are associated with peripheral vascular disease, coronary artery disease, MI, and stroke [226]. The first occurrence of a non-fatal MI, any nonfatal stroke, and cardiovascular death were defined as the primary endpoints. Regarding these primary endpoints, treatment with $150 \mathrm{mg}$ and $300 \mathrm{mg}$ revealed HR for the primary IL- $1 \beta$ neutralizing antibody with $15 \%$ and $14 \%$ risk reduction, respectively [225]. However, re-analysis of the CANTOS trial further showed that patients receiving canakinumab were still at increased risk of recurrent cardiovascular events, possibly mediated by IL-18 and IL-6, which are also potential targets for future treatment strategy for CVD [227]. Taking this into account, targeting multiple signaling pathways and the formation of cytokines could be promising strategies in the treatment of CVD. This raises the question of whether vitamin E, as a broad-range anti-inflammatory agent, is still to be considered a promising intervention in CVD and atherothrombosis.

In contrast to the CANTOS trial, the clinical Cardiovascular Inflammation Reduction Trial (CIRT) targeted a broader range of pro-inflammatory processes using the anti-rheumatic compound methotrexate, which is known to reduce cytokine secretion and the generation of ROS [228]. After the primary prevention of rheumatoid arthritis, off-target effects such as a reduction in cardiovascular events were detected with the methotrexate treatment using the normal dosing range of 5-30 mg per week for rheumatoid arthritis [229]. In earlier studies, methotrexate was associated with a $21 \%$ risk 
reduction in CVD $(p<0.001)$ and an $18 \%$ lower risk of MI $(p=0.01)$ among patients with rheumatoid arthritis, psoriasis, or polyarthritis [230]. However, a recent clinical trial by Ridker et al. enrolled patients with previous MI or multivessel coronary disease and additional DMT2 or MetS; after a total study duration of 8 months applying methotrexate at $15 \mathrm{mg}$ per week, followed by $20 \mathrm{mg}$ per week, clinical parameters were assessed. Neither any markers of inflammation, such as IL-6, IL-1 $\beta$, or CRP, nor the cardiovascular event rate were altered by methotrexate [231]. The differences in outcomes of this methotrexate trial compared with the above-described trial with canakinumab could be the result of different inflammatory disease stages in the enrolled patients. Beneficial effects of methotrexate were observed in patients suffering from rheumatoid arthritis, psoriasis, or polyarthritis, which are associated with a certain level of inflammation, whereas in the CIRT patients diagnosed with DMT2 and MetS were enrolled. Since the degree of inflammation is a key player in CVD, the study outcomes may have been altered due to this difference [144,225]. A beneficial effect of methotrexate on the cardiovascular event rate seems to be present in arthritis patients, whereas in others with a less inflammatory status beneficial effects may not be expected.

Another approach in the prevention of cardiovascular events is the drug colchicine, which has long been in use for the treatment of gout and pericarditis. Among other properties, colchicine attenuates the production of inflammatory chemokines and the activation of the inflammasome NLRP3 [232,233]. The first clinical trial evaluating the effects of low-dose colchicine (LoDoCo) in patients with stable coronary disease revealed a significant reduction in cardiovascular events (HR 0.33; 95\% CI 0.18, 0.59; $p<0.001$ ) in patients supplemented with $0.5 \mathrm{mg}$ colchicine per day for 3 years compered to non-supplemented patients [234]. The recent Colchicine Cardiovascular Outcomes Trial (COLCOT) investigated the efficacy of the same dose of colchicine for 2 years after the occurrence of an MI [235]. The HR for a defined composite of primary endpoints, death from cardiovascular causes, resuscitated cardiac arrest, MI, stroke, or urgent hospitalization for angina leading to coronary revascularization, decreased to 0.77 (95\% CI 0.61, 0.96; $p=0.02$ ). However, single HR for primary endpoints showed decreasing trends for death from cardiovascular causes (HR 0.84, 95\% CI 0.46, 1.52) and MI (HR 0.91, $95 \%$ CI $0.68,1.21$ ) [235].

Taken together, we can conclude that the success of anti-inflammatory therapies seems to be dependent on the initial status of oxidative and inflammatory stress, as measured by an increased CRP level. Subjects with persistently elevated inflammatory states seem to benefit most from therapeutic strategies targeting inflammation regarding the related risk of CVD.

\subsection{Importance of Cohort Selection and Hp 2-2 Genotype}

The protein haptoglobin $(\mathrm{Hp})$ circulates in the blood and acts as an antioxidant which binds free hemoglobin and thus protects tissues from iron-induced oxidation [236]. In humans, the homozygous genotypes Hp 1-1 and Hp 2-2 and the heterozygous genotypes Hp 2-1 and Hp 2-1m exist, with Hp 2-2 being the most common genotype [237,238]. Compared to Hp 1-1 and Hp 1-2, Hp 2-2 is considered an independent risk factor for cardiovascular outcomes among individuals with DMT2 [239]. The analysis of the Strong Heart Study (SHS) in 4549 Native American showed the following susceptibilities to CVD in DMT2 patients: Hp 1-1 (OR 1.0) < Hp 1-2 (OR 1.63) < Hp 2-2 (OR 4.96; $p=0.002)$ [239]. A similar trend was present in non-diabetic subjects, which supports the hypothesis that Hp 1-1 offers superior antioxidant protection [236]. Furthermore, Hp 2-2 is associated with an increased level of CRP and carotid arterial IMT, a marker for CVD, in a cohort from Singapore [238] and the Diabetes Heart Study conducted in European Americans [240]. However, the study of De Bacquer et al. reported an increased risk of cardiovascular events in non-diabetic patients with the Hp 1-1 phenotype in the Belgian Interuniversity Research on Nutrition and Health (BIRNH) survey [241]. The relevance of the Hp genotype for the cardiovascular risk in patients suffering DMT1 remains elusive [242].

Different $\mathrm{Hp}$ genotypes are associated with different oxidative conditions; thus, proper sample collection is crucial in human studies investigating the cardioprotective effects of vitamin E. A meta-analysis of the Heart Outcomes Prevention Evaluation (HOPE) trial and the Israel 
Cardiovascular Events Reduction with Vitamin E (ICARE) study revealed significant reductions in cardiovascular death, MI, and stroke (OR $0.58,95 \%$ CI $0.40,0.86 ; p=0.006$ ) in diabetic individuals with the Hp 2-2 genotype supplemented with vitamin E compared to diabetics with the Hp 1-1 or Hp 2-1 genotype [243]. Further, including the Woman's Health Study (WHS) in this analysis, the odds ratio was $0.66(95 \% \mathrm{CI} 0.48,0.90 ; p=0.009)$ [244]. A recent study by Asleh et al. confirmed a reduction in cardiovascular events in patients with DMT2 and the Hp 2-2 genotype (OR: 0.66, 95\% CI 0.45, 0.95; $p=0.025$ ) via high-dose vitamin E supplementation [245]. In contrast, in subjects with non-Hp 2-2 genotypes, no beneficial effects of vitamin E supplementation on the cardiovascular event rate has been observed.

Beyond the Hp2-2 genotype, other genotypes may affect the outcome of vitamin E supplementation. Several studies demonstrated an impact of e.g., apolipoprotein E (ApoE) genotype [246-248] and Paraoxonase 1 (PON-1) genotype [249,250] on vitamin E. For example, the apoE4 genotype represents a significant risk factor for CVD. ApoE4 may be associated with lower vitamin $\mathrm{E}$ retention in peripheral tissues, possibly related to a combination of several factors: An increased $\alpha$-TOH retention in LDL, an impaired cellular vitamin E delivery system, a reduced expression of lipoprotein receptors, and an increased intracellular degradation of vitamin E [248].

In summary, the Hp 2-2 genotype is associated with increased oxidative stress and an increased risk of cardiovascular events, especially in diabetic patients. Therefore, vitamin E supplementation in this sub-cohort of patients seems to be promising in protecting from CVD. Re-analyzing previous RCTs with respect to Hp genotypes could provide insights into the differences in the beneficial effects of vitamin E supplementation.

\subsection{High-Dose Supplementation of Vitamin E vs. Balancing Vitamin E Deficiency}

Long-term supplementation of vitamin E to prevent cardiovascular events has been intensively studied and reported to be inefficient in many human intervention and correlation studies. Various doses of vitamin E, ranging from 16.5 to $2000 \mathrm{IU}$ per day have been tested. A meta-analysis including 135,967 objects in 19 clinical trials investigated the relationship between vitamin E dosage and all-cause mortality. Eleven trials supplemented with high-dosage vitamin E ( $\geq 400 \mathrm{IU}$ per day), and nine of these 11 trials showed an increased risk for all-cause mortality [29]. Long-term supplementation of high-dosage vitamin $\mathrm{E}$ is therefore not recommended.

Only specific risk groups may need a higher vitamin E intake to receive the same vitamin E plasma level as healthy subjects. For example, patients with MetS showed higher requirements, due to greater inflammation and oxidative stress that limit absorption and/or impair hepatic $\alpha$-tocopherol trafficking [251]. However, this higher intake does not mean dosages greater than the FDA-approved dose of $400 \mathrm{IU}$ per day, which is considered safe in humans without adverse effects.

In contrast, special conditions like acute MI may lead to higher demand for vitamin E. As mentioned in Section 4.5, vitamin E plasma levels drop within the first $48 \mathrm{~h}$ after acute MI and therapeutic reperfusion also leads to increased consumption of vitamin E. Even low doses of vitamin E, delivered at the crucial time around reperfusion to meet the higher vitamin $E$ demand, have been reported to be highly effective and cardioprotective in the preclinical setting of an acute MI [195]. Thus, the duration and time of supplementation, as well as the dosage, of vitamin E could be crucial for the beneficial or deleterious effects of vitamin E therapy.

Overall, long-term supplementation of vitamin E fails to prevent cardiovascular events, as shown in many correlation and intervention studies, and high-dose vitamin E supplementation is not recommended. Supplementation of vitamin $\mathrm{E}$ in conditions of higher demand like the setting of an acute MI and during reperfusion could be a beneficial therapeutic strategy.

\section{Merits and Limitations}

The focus in this review is on the effects of vitamin $\mathrm{E}$ in association with the risk factors for CVD and CVD itself, particularly MI. As such, we summarize the relationships between vitamin E levels 
and various risk factors for CVD, and discuss potential reasons why the association of low vitamin $\mathrm{E}$ levels and cardiovascular risk found in observational studies could not be transferred to successful treatment options in interventional studies. We hypothesize that vitamin E application in the acute treatment of myocardial infarction is likely more successful than in chronic supplementation aiming at the prevention of cardiovascular events.

We decided to exclude stroke, as it is an often discussed, controversial, and extensive field itself, which goes beyond our review. For more interest in stroke, we refer readers to other reviews and meta-analyses focusing on stroke and vitamin E [252-256].

\section{Conclusions}

Overall, extensive studies have tested the potential of vitamin E to prevent cardiovascular events, in particular MI. Promising data from observational studies have reported associations between higher vitamin $\mathrm{E}$ intake and higher vitamin E plasma levels and lower risk of cardiovascular events, as well as promising associations between vitamin $\mathrm{E}$ intake/plasma levels and risk factors for CVD, such as hypertension, hyperlipidemia, venous thrombosis, DMT2, NAFLD/NASH, age, obesity, and metabolic syndrome. These effects have not been confirmed in interventional trials assessing the impact of vitamin E supplementation on the CVD risk factors hyperlipidemia, hypertension, obesity, and metabolic syndrome, as well as on CVD outcomes. A few interventional trials assessing the effect on vitamin $\mathrm{E}$ supplementation on venous thrombosis showed controversial results and, in our opinion, more studies in this field are required. Positive effects of vitamin E supplementation could be observed in adult NAFLD/NASH patients, as well as in DMT2 patients. Further RCTs for DMT2 patients and vitamin E supplementation are warranted. Overall, many clinical trials have presented controversial results, suggesting that long-term vitamin E supplementation is not a favorable therapeutic strategy, and that high-dose vitamin E supplementation is not to be recommended. Furthermore, the results from vitamin E interventional trials also seem to be highly controversial, mainly due to the wide range of different parameters studied. Critical parameters for RCTs are cohort selection, duration, timing and dosage of vitamin E treatment, the different forms of vitamin $E$, the synergistic effects of vitamin $E$, and the metabolism of vitamin E. These parameters need to be critically reviewed based on the outcome of previous trials in the specific clinical setting and need to be thoroughly assessed and considered for future and hopefully more successful study designs.

Vitamin E therapy in the setting of an acute cardiac ischemic event and during reperfusion, when the vitamin E plasma level is down and the demand for vitamin $\mathrm{E}$ is increased, has shown promising preclinical effects on infarct size and preservation of cardiac function. The success of vitamin $\mathrm{E}$ therapy could potentially be significantly improved by treatment in the acute setting, along with vitamin E deficiency.

Author Contributions: Conceptualization, M.Z., M.W., S.L. and K.P.; writing-original draft preparation, M.Z., M.W.; writing—review and editing, M.Z., M.W., S.L. and K.P.; visualization, M.Z., M.W.; supervision, S.L. and K.P.; project administration, S.L. and K.P.; funding acquisition, S.L. and K.P. All authors have read and agreed to the published version of the manuscript.

Funding: Deutsche Forschungsgemeinschaft: RTG 1715, Collaborative Research Centre (SFB): 1278, German Federal Ministry of Education and Research: 01EA1411A, Free State of Thuringia and the European Social Fund: 2019 FGR 0095, NHMRC: Investigator L3 fellowship.

Conflicts of Interest: The authors declare no conflict of interest.

\section{References}

1. Libby, P.; Ridker, P.M.; Maseri, A. Inflammation and atherosclerosis. Circulation 2002, 105, 1135-1143. [CrossRef] [PubMed]

2. Marchio, P.; Guerra-Ojeda, S.; Vila, J.M.; Aldasoro, M.; Victor, V.M.; Mauricio, M.D. Targeting early atherosclerosis: A focus on oxidative stress and inflammation. Oxid. Med. Cell. Longev. 2019, 2019, 1-32. [CrossRef] [PubMed] 
3. Baratchi, S.; Khoshmanesh, K.; Woodman, O.L.; Potocnik, S.; Peter, K.; McIntyre, P. Molecular sensors of blood flow in endothelial cells. Trends Mol. Med. 2017, 23, 850-868. [CrossRef] [PubMed]

4. Halliwell, B. Biochemistry of oxidative stress. Biochem. Soc. Trans. 2007, 35, 1147-1150. [CrossRef]

5. Murr, C.; Winklhofer-Roob, B.M.; Schroecksnadel, K.; Maritschnegg, M.; Mangge, H.; Böhm, B.O.; Winkelmann, B.R.; März, W.; Fuchs, D. Inverse association between serum concentrations of neopterin and antioxidants in patients with and without angiographic coronary artery disease. Atherosclerosis 2009, 202, 543-549. [CrossRef]

6. Neuzil, J.; Kågedal, K.; Andera, L.; Weber, C.; Brunk, U.T. Vitamin E analogs: A new class of multiple action agents with anti-neoplastic and anti-atherogenic activity. Apoptosis 2002, 7, 179-187. [CrossRef]

7. Burton, G.W.; Ingold, K.U. Vitamin E as an in vitro and in vivo antioxidant. Ann. N. Y. Acad. Sci. 1989, 570, 7-22. [CrossRef]

8. Evans, H.M.; Bishop, K.S. On the existence of a hotherto unrecognized dietary factor essential for reproduction. Science 1922, 56, 650-651. [CrossRef]

9. Azzi, A. Many tocopherols, one vitamin E. Mol. Asp. Med. 2018, 61, 92-103. [CrossRef]

10. Traber, M.G.; Kayden, H.J. Preferential incorporation of alpha-tocopherol vs gamma-tocopherol in human lipoproteins. Am. J. Clin. Nutr. 1989, 49, 517-526. [CrossRef]

11. Schmölz, L.; Birringer, M.; Lorkowski, S.; Wallert, M. Complexity of vitamin E metabolism. World J. Biol. Chem. 2016, 7, 14-43. [CrossRef] [PubMed]

12. Institute of Medicine (US) Panel on Dietary Antioxidants and Related Compounds. Dietary Reference Intakes for Vitamin C, Vitamin E, Selenium, and Carotenoids; National Academies Press (US): Washington, DC, USA, 2000; ISBN 978-0-309-06949-6.

13. Traber, M.G. Vitamin E inadequacy in humans: Causes and consequences. Adv. Nutr. 2014, 5, 503-514. [CrossRef] [PubMed]

14. Shils, M.; Shike, M.; Ross, A.; Caballero, B.; Cousins, R. Nutrition in Health and Disease, 11th ed.; Lippincott Williams and Wilkins: Philadelphia, PA, USA, 2012; ISBN 1-60547-461-4.

15. Grebenstein, N.; Schumacher, M.; Graeve, L.; Frank, J. $\alpha$-Tocopherol transfer protein is not required for the discrimination against $\gamma$-tocopherol in vivo but protects it from side-chain degradation in vitro. Mol. Nutr. Food Res. 2014, 58, 1052-1060. [CrossRef] [PubMed]

16. Zingg, J.-M.; Meydani, M.; Azzi, A. alpha-Tocopheryl phosphate-an active lipid mediator? Mol. Nutr. Food Res. 2010, 54, 679-692. [CrossRef] [PubMed]

17. Gianello, R.; Libinaki, R.; Azzi, A.; Gavin, P.D.; Negis, Y.; Zingg, J.-M.; Holt, P.; Keah, H.-H.; Griffey, A.; Smallridge, A.; et al. Alpha-tocopheryl phosphate: A novel, natural form of vitamin E. Free Radic. Biol. Med. 2005, 39, 970-976. [CrossRef]

18. Traber, M.G.; Rudel, L.L.; Burton, G.W.; Hughes, L.; Ingold, K.U.; Kayden, H.J. Nascent VLDL from liver perfusions of cynomolgus monkeys are preferentially enriched in RRR-compared with SRR-alpha-tocopherol: Studies using deuterated tocopherols. J. Lipid Res. 1990, 31, 687-694.

19. Parker, R.S.; Sontag, T.J.; Swanson, J.E. Cytochrome P4503A-dependent metabolism of tocopherols and inhibition by sesamin. Biochem. Biophys. Res. Commun. 2000, 277, 531-534. [CrossRef]

20. Sontag, T.J.; Parker, R.S. Cytochrome P450 $\omega$-hydroxylase pathway of tocopherol catabolism: Novel mechanism of regulation of vitamin E status. J. Biol. Chem. 2002, 277, 25290-25296. [CrossRef]

21. Birringer, M.; Pfluger, P.; Kluth, D.; Landes, N.; Brigelius-Flohé, R. Identities and differences in the metabolism of tocotrienols and tocopherols in HepG2 Cells. J. Nutr. 2002, 132, 3113-3118. [CrossRef]

22. Kiyose, C.; Saito, H.; Kaneko, K.; Hamamura, K.; Tomioka, M.; Ueda, T.; Igarashi, O. Alpha-tocopherol affects the urinary and biliary excretion of 2,7,8-trimethyl-2 (2'-carboxyethyl)-6-hydroxychroman, gamma-tocopherol metabolite, in rats. Lipids 2001, 36, 467-472. [CrossRef]

23. Schultz, M.; Leist, M.; Petrzika, M.; Gassmann, B.; Brigelius-Flohé, R. Novel urinary metabolite of alpha-tocopherol, 2,5,7,8-tetramethyl-2(2'-carboxyethyl)-6-hydroxychroman, as an indicator of an adequate vitamin E supply? Am. J. Clin. Nutr. 1995, 62, 1527S-1534S. [CrossRef] [PubMed]

24. Lebold, K.M.; Ang, A.; Traber, M.G.; Arab, L. Urinary $\alpha$-carboxyethyl hydroxychroman can be used as a predictor of $\alpha$-tocopherol adequacy, as demonstrated in the Energetics Study. Am. J. Clin. Nutr. 2012, 96, 801-809. [CrossRef] [PubMed]

25. Birringer, M.; EyTina, J.H.; Salvatore, B.A.; Neuzil, J. Vitamin E analogues as inducers of apoptosis: Structure-function relation. Br. J. Cancer 2003, 88, 1948-1955. [CrossRef] [PubMed] 
26. Traber, M.G.; Atkinson, J. Vitamin E, antioxidant and nothing more. Free Radic. Biol. Med. 2007, 43, 4-15. [CrossRef] [PubMed]

27. Brigelius-Flohé, R. Vitamin E: The shrew waiting to be tamed. Free Radic. Biol. Med. 2009, 46, 543-554. [CrossRef]

28. Kontush, A.; Finckh, B.; Karten, B.; Kohlschütter, A.; Beisiegel, U. Antioxidant and prooxidant activity of alpha-tocopherol in human plasma and low density lipoprotein. J. Lipid Res. 1996, 37, 1436-1448.

29. Miller, E.R.; Pastor-Barriuso, R.; Dalal, D.; Riemersma, R.A.; Appel, L.J.; Guallar, E. Meta-analysis: High-dosage vitamin E supplementation may increase all-cause mortality. Ann. Intern. Med. 2005, 142, 37-46. [CrossRef]

30. Pearson, P.; Lewis, S.A.; Britton, J.; Young, I.S.; Fogarty, A. The pro-oxidant activity of high-dose vitamin E supplements in vivo. BioDrugs 2006, 20, 271-273. [CrossRef]

31. Gerss, J.; Köpcke, W. The questionable association of vitamin E supplementation and mortality-inconsistent results of different meta-analytic approaches. Cell. Mol. Biol. (Noisy-Le-Grand) 2009, 55 Suppl. 1, OL1111-OL1120.

32. Meagher, E.A.; Barry, O.P.; Lawson, J.A.; Rokach, J.; FitzGerald, G.A. Effects of vitamin E on lipid peroxidation in healthy persons. JAMA 2001, 285, 1178-1182. [CrossRef]

33. Roberts, L.J.; Oates, J.A.; Linton, M.F.; Fazio, S.; Meador, B.P.; Gross, M.D.; Shyr, Y.; Morrow, J.D. The relationship between dose of vitamin $\mathrm{E}$ and suppression of oxidative stress in humans. Free Radic. Biol. Med. 2007, 43, 1388-1393. [CrossRef] [PubMed]

34. Davi, G.; Alessandrini, P.; Mezzetti, A.; Minotti, G.; Bucciarelli, T.; Costantini, F.; Cipollone, F.; Bon, G.B.; Ciabattoni, G.; Patrono, C. In vivo formation of 8-Epi-prostaglandin F2 alpha is increased in hypercholesterolemia. Arter. Thromb. Vasc. Biol. 1997, 17, 3230-3235. [CrossRef] [PubMed]

35. Hathcock, J.N.; Azzi, A.; Blumberg, J.; Bray, T.; Dickinson, A.; Frei, B.; Jialal, I.; Johnston, C.S.; Kelly, F.J.; Kraemer, K.; et al. Vitamins $\mathrm{E}$ and $\mathrm{C}$ are safe across a broad range of intakes. Am. J. Clin. Nutr. 2005, 81, 736-745. [CrossRef]

36. Hickman, K.C.D.; Harris, P.L. Tocopherol interrelationships. In Advances in Enzymology and Related Areas of Molecular Biology; Nord, F.F., Ed.; John Wiley \& Sons, Inc.: Hoboken, NJ, USA, 2006; pp. 469-524. ISBN 978-0-470-12251-8.

37. Azzi, A. Molecular mechanism of alpha-tocopherol action. Free Radic. Biol. Med. 2007, 43, 16-21. [CrossRef] [PubMed]

38. Azzi, A.; Ricciarelli, R.; Zingg, J.M. Non-antioxidant molecular functions of alpha-tocopherol (vitamin E). FEBS Lett. 2002, 519, 8-10. [CrossRef]

39. Schächinger, V.; Zeiher, A.M. Atherogenesis-Recent insights into basic mechanisms and their clinical impact. Nephrol. Dial. Transpl. 2002, 17, 2055-2064. [CrossRef]

40. Weber, C.; Noels, H. Atherosclerosis: Current pathogenesis and therapeutic options. Nat. Med. 2011, 17, 1410-1422. [CrossRef]

41. Htun, N.M.; Chen, Y.C.; Lim, B.; Schiller, T.; Maghzal, G.J.; Huang, A.L.; Elgass, K.D.; Rivera, J.; Schneider, H.G.; Wood, B.R.; et al. Near-infrared autofluorescence induced by intraplaque hemorrhage and heme degradation as marker for high-risk atherosclerotic plaques. Nat. Commun. 2017, 8, 75. [CrossRef]

42. Rafieian-Kopaei, M.; Setorki, M.; Doudi, M.; Baradaran, A.; Nasri, H. Atherosclerosis: Process, indicators, risk factors and new hopes. Int. J. Prev. Med. 2014, 5, 927-946.

43. Nording, H.M.; Seizer, P.; Langer, H.F. Platelets in Inflammation and Atherogenesis. Front. Immunol. $2015,6$. [CrossRef]

44. Palasubramaniam, J.; Wang, X.; Peter, K. Myocardial infarction-From atherosclerosis to thrombosis. Arterioscler. Thromb. Vasc. Biol. 2019, 39, e176-e185. [CrossRef]

45. Benjamin, E.J.; Muntner, P.; Alonso, A.; Bittencourt, M.S.; Callaway, C.W.; Carson, A.P.; Chamberlain, A.M.; Chang, A.R.; Cheng, S.; Das Sandeep, R.; et al. Heart disease and stroke statistics-2019 update: A report from the American Heart Association. Circulation 2019, 139, e56-e528. [CrossRef] [PubMed]

46. Stewart, J.; Manmathan, G.; Wilkinson, P. Primary prevention of cardiovascular disease: A review of contemporary guidance and literature. JRSM Cardiovasc. Dis. 2017, 6. [CrossRef] [PubMed]

47. Batty, G.D.; Kivimäki, M.; Bell, S. Comparison of risk factors for coronary heart disease morbidity versus mortality. Eur. J. Prev. Cardiol. 2019, 2047487319882512. [CrossRef] 
48. Knuuti, J.; Wijns, W.; Saraste, A.; Capodanno, D.; Barbato, E.; Funck-Brentano, C.; Prescott, E.; Storey, R.F.; Deaton, C.; Cuisset, T.; et al. 2019 ESC Guidelines for the diagnosis and management of chronic coronary syndromes: The Task Force for the diagnosis and management of chronic coronary syndromes of the European Society of Cardiology (ESC). Eur. Heart J. 2020, 41, 407-477. [CrossRef]

49. Thygesen, K.; Alpert, J.S.; Jaffe, A.S.; Chaitman, B.R.; Bax, J.J.; Morrow, D.A.; White, H.D.; Thygesen, K.; Alpert, J.S.; Jaffe, A.S.; et al. Fourth universal definition of myocardial infarction (2018). Eur. Heart J. 2019, 40, 237-269. [CrossRef]

50. Jennings, R.B.; Sommers, H.M.; Smyth, G.A.; Flack, H.A.; Linn, H. Myocardial necrosis induced by temporary occlusion of a coronary artery in the dog. Arch. Pathol. 1960, 70, 68-78.

51. Ziegler, M.; Xu, X.; Yap, M.L.; Hu, H.; Zhang, J.; Peter, K. A self-assembled fluorescent nanoprobe for imaging and therapy of cardiac ischemia/reperfusion injury. Adv. Ther. 2019, 2, 1800133. [CrossRef]

52. van Nieuwenhoven, F.A.; Turner, N.A. The role of cardiac fibroblasts in the transition from inflammation to fibrosis following myocardial infarction. Vasc. Pharm. 2013, 58, 182-188. [CrossRef]

53. Kuwabara, A.; Nakade, M.; Tamai, H.; Tsuboyama-Kasaoka, N.; Tanaka, K. The association between vitamin E intake and hypertension: Results from the re-analysis of the National Health and Nutrition Survey. J. Nutr. Sci. Vitam. 2014, 60, 239-245. [CrossRef]

54. Boshtam, M.; Rafiei, M.; Sadeghi, K.; Sarraf-Zadegan, N. Vitamin E can reduce blood pressure in mild hypertensives. Int. J. Vitam. Nutr. Res. 2002, 72, 309-314. [CrossRef]

55. Santhoshakumari, T.M.J.; Mathivanan, J.; Jeyalakshmi, J. Role of vitamin C and vitamin E on hypertension. Asian J. Pharm. Clin. Res. 2019, 95-98. [CrossRef]

56. Palumbo, G.; Avanzini, F.; Alli, C.; Roncaglioni, M.C.; Ronchi, E.; Cristofari, M.; Capra, A.; Rossi, S.; Nosotti, L.; Costantini, C.; et al. Effects of vitamin E on clinic and ambulatory blood pressure in treated hypertensive patients. Collaborative Group of the Primary Prevention Project (PPP)-Hypertension study. Am. J. Hypertens. 2000, 13, 564-567. [CrossRef]

57. Mihalj, M.; Tadzic, R.; Vcev, A.; Rucevic, S.; Drenjancevic, I. Blood pressure reduction is associated with the changes in oxidative stress and endothelial activation in hypertension, regardless of antihypertensive therapy. KBR 2016, 41, 721-735. [CrossRef] [PubMed]

58. Barbagallo, M.; Dominguez, L.J.; Tagliamonte, M.R.; Resnick, L.M.; Paolisso, G. Effects of vitamin E and glutathione on glucose metabolism. Hypertension 1999, 34, 1002-1006. [CrossRef] [PubMed]

59. Cangemi, R.; Loffredo, L.; Carnevale, R.; Perri, L.; Patrizi, M.P.; Sanguigni, V.; Pignatelli, P.; Violi, F. Early decrease of oxidative stress by atorvastatin in hypercholesterolaemic patients: Effect on circulating vitamin E. Eur. Heart J. 2008, 29, 54-62. [CrossRef] [PubMed]

60. Shin, M.-J.; Chung, N.; Lee, J.H.; Jang, Y.; Park, E.; Jeon, K.-I.; Chung, J.H.; Seo, B.-Y. Effects of simvastatin on plasma antioxidant status and vitamins in hypercholesterolemic patients. Int. J. Cardiol. 2007, 118, 173-177. [CrossRef] [PubMed]

61. Blom, D.J.; Djedjos, C.S.; Monsalvo, M.L.; Bridges, I.; Wasserman, S.M.; Scott, R.; Roth, E. Effects of evolocumab on vitamin E and steroid hormone levels: Results from the 52-Week, phase 3, double-blind, randomized, placebo-controlled DESCARTES study. Circ. Res. 2015, 117, 731-741. [CrossRef]

62. Liu, C.-S.; Lii, C.-K.; Chang, L.-L.; Kuo, C.-L.; Cheng, W.-L.; Su, S.-L.; Tsai, C.-W.; Chen, H.-W. Atorvastatin increases blood ratios of vitamin E/low-density lipoprotein cholesterol and coenzyme Q10/low-density lipoprotein cholesterol in hypercholesterolemic patients. Nutr. Res. 2010, 30, 118-124. [CrossRef]

63. Leonard, S.W.; Joss, J.D.; Mustacich, D.J.; Blatt, D.H.; Lee, Y.S.; Traber, M.G. Effects of vitamin E on cholesterol levels of hypercholesterolemic patients receiving statins. Am. J. Health Syst. Pharm. 2007, 64, 2257-2266. [CrossRef]

64. Glynn, R.J.; Ridker, P.M.; Goldhaber, S.Z.; Zee Robert, Y.L.; Buring, J.E. Effects of random allocation to vitamin E supplementation on the occurrence of venous thromboembolism. Circulation 2007, 116, 1497-1503. [CrossRef] [PubMed]

65. Vučković, B.A.; van Rein, N.; Cannegieter, S.C.; Rosendaal, F.R.; Lijfering, W.M. Vitamin supplementation on the risk of venous thrombosis: Results from the MEGA case-control study. Am. J. Clin. Nutr 2015, 101, 606-612. [CrossRef] [PubMed]

66. Ortega, R.M.; Requejo, A.M.; López-Sobaler, A.M.; Andrés, P.; Navia, B.; Perea, J.M.; Robles, F. Cognitive function in elderly people is influenced by vitamin E status. J. Nutr. 2002, 132, 2065-2068. [CrossRef] 
67. Vatassery, G.T.; Johnson, G.J.; Krezowski, A.M. Changes in vitamin E concentrations in human plasma and platelets with age. J. Am. Coll. Nutr. 1983, 2, 369-375. [CrossRef] [PubMed]

68. Capuron, L.; Moranis, A.; Combe, N.; Cousson-Gélie, F.; Fuchs, D.; De Smedt-Peyrusse, V.; Barberger-Gateau, P.; Layé, S. Vitamin E status and quality of life in the elderly: Influence of inflammatory processes. Br. J. Nutr. 2009, 102, 1390-1394. [CrossRef]

69. Requejo, A.M.; Andrés, P.; Redondo, M.R.; Mena, M.C.; Navia, B.; Perea, J.M.; Lopez-Sobaler, A.M.; Ortega, R.M. Vitamin E status in a group of elderly people from Madrid. J. Nutr. Health Aging 2002, 6, $72-74$.

70. Rudman, D.; Abbasi, A.A.; Isaacson, K.; Karpiuk, E. Observations on the nutrient intakes of eating-dependent nursing home residents: Underutilization of micronutrient supplements. J. Am. Coll. Nutr. 1995, 14, 604-613. [CrossRef]

71. De la Fuente, M.; Hernanz, A.; Guayerbas, N.; Victor, V.M.; Arnalich, F. Vitamin E ingestion improves several immune functions in elderly men and women. Free Radic. Res. 2008, 42, 272-280. [CrossRef]

72. da Silva, I.T.; de Queiroz Mello, A.P.; Sanches, L.B.; Abdalla, D.S.P.; Damasceno, N.R.T. Is plasma alpha-tocopherol associated with electronegative LDL in obese adolescents? J. Nutr. Sci. Vitam. 2013, 59, 100-107. [CrossRef]

73. Mehmetoglu, I.; Yerlikaya, F.H.; Kurban, S. Correlation between vitamin A, E, coenzyme Q(10) and degree of insulin resistance in obese and non-obese subjects. J. Clin. Biochem. Nutr. 2011, 49, 159-163. [CrossRef]

74. Kuno, T.; Hozumi, M.; Morinobu, T.; Murata, T.; Mingci, Z.; Tamai, H. Antioxidant vitamin levels in plasma and low density lipoprotein of obese girls. Free Radic. Res. 1998, 28, 81-86. [CrossRef] [PubMed]

75. Strauss, R.S. Comparison of serum concentrations of $\alpha$-tocopherol and $\beta$-carotene in a cross-sectional sample of obese and nonobese children (NHANES III). J. Pediatr. 1999, 134, 160-165. [CrossRef]

76. Molnár, D.; Decsi, T.; Koletzko, B. Reduced antioxidant status in obese children with multimetabolic syndrome. Int. J. Obes. Relat. Metab. Disord. 2004, 28, 1197-1202. [CrossRef] [PubMed]

77. Gunanti, I.R.; Marks, G.C.; Al-Mamun, A.; Long, K.Z. Low serum concentrations of carotenoids and vitamin E are associated with high adiposity in Mexican-American children. J. Nutr. 2014, 144, 489-495. [CrossRef]

78. Schneider, M.; Verges, B.; Klein, A.; Miller, E.R.; Deckert, V.; Desrumaux, C.; Masson, D.; Gambert, P.; Brun, J.-M.; Fruchart-Najib, J.; et al. Alterations in plasma vitamin E distribution in type 2 diabeticpatients with elevated plasma phospholipid transfer protein Activity. Diabetes 2004, 53, 2633-2639. [CrossRef]

79. Galvan, A.Q.; Muscelli, E.; Catalano, C.; Natali, A.; Sanna, G.; Masoni, A.; Bernardini, B.; Barsacchi, R.; Ferrannini, E. Insulin decreases circulating vitamin E levels in humans. Metab. Clin. Exp. 1996, 45, 998-1003. [CrossRef]

80. Kollerits, B.; Lamina, C.; Huth, C.; Marques-Vidal, P.; Kiechl, S.; Seppälä, I.; Cooper, J.; Hunt, S.C.; Meisinger, C.; Herder, C.; et al. Plasma concentrations of afamin are associated with prevalent and incident type 2 diabetes: A pooled analysis in more than 20,000 individuals. Diabetes Care 2017, 40, 1386-1393. [CrossRef]

81. Mayer-Davis, E.J.; Costacou, T.; King, I.; Zaccaro, D.J.; Bell, R.A. Plasma and dietary vitamin E in relation to incidence of type 2 diabetes: The insulin resistance and atherosclerosis study (IRAS). Diabetes Care 2002, 25, 2172-2177. [CrossRef]

82. Škrha, J.; Prázný, M.; Hilgertová, J.; Weiserová, H. Serum $\alpha$-tocopherol and ascorbic acid concentrations in Type 1 and Type 2 diabetic patients with and without angiopathy. Clin. Chim. Acta 2003, 329, 103-108. [CrossRef]

83. Salonen, R.M.; Nyyssönen, K.; Kaikkonen, J.; Porkkala-Sarataho, E.; Voutilainen, S.; Rissanen, T.H.; Tuomainen, T.-P.; Valkonen, V.-P.; Ristonmaa, U.; Lakka, H.-M.; et al. Six-year effect of combined vitamin C and $\mathrm{E}$ supplementation on atherosclerotic progression: The antioxidant supplementation in atherosclerosis prevention (ASAP) study. Circulation 2003, 107, 947-953. [CrossRef]

84. Eljaoudi, R.; Elomri, N.; Laamarti, M.; Cherrah, Y.; Amezyane, T.; Ghafir, D.; Ibrahimi, A. Antioxidants status in type 2 diabetic patients in Morocco. Turk. J. Med. Sci. 2017, 47, 782-788. [CrossRef]

85. Nourooz-Zadeh, J.; Rahimi, A.; Tajaddini-Sarmadi, J.; Tritschler, H.; Rosen, P.; Halliwell, B.; Betteridge, D.J. Relationships between plasma measures of oxidative stress and metabolic control in NIDDM. Diabetologia 1997, 40, 647-653. [CrossRef] [PubMed]

86. Rafighi, Z.; Shiva, A.; Arab, S.; Mohd Yousof, R. Association of dietary vitamin C and E intake and antioxidant enzymes in type 2 diabetes mellitus patients. GJHS 2013, 5, 183. [CrossRef] [PubMed] 
87. Manning, P.J.; Sutherland, W.H.F.; Walker, R.J.; Williams, S.M.; De Jong, S.A.; Ryalls, A.R.; Berry, E.A. Effect of high-dose vitamin E on insulin resistance and associated parameters in overweight subjects. Diabetes Care 2004, 27, 2166-2171. [CrossRef]

88. Xu, R.; Zhang, S.; Tao, A.; Chen, G.; Zhang, M. Influence of vitamin E supplementation on glycaemic control: A meta-analysis of randomised controlled trials. PLoS ONE 2014, 9, e95008. [CrossRef]

89. Erhardt, A.; Stahl, W.; Sies, H.; Lirussi, F.; Donner, A.; Häussinger, D. Plasma levels of vitamin E and carotenoids are decreased in patients with Nonalcoholic Steatohepatitis (NASH). Eur. J. Med. Res. 2011, 16, 76-78. [CrossRef]

90. Machado, M.V.; Ravasco, P.; Jesus, L.; Marques-Vidal, P.; Oliveira, C.R.; Proença, T.; Baldeiras, I.; Camilo, M.E.; Cortez-Pinto, H. Blood oxidative stress markers in non-alcoholic steatohepatitis and how it correlates with diet. Scand. J. Gastroenterol. 2008, 43, 95-102. [CrossRef]

91. Violet, P.-C.; Ebenuwa, I.C.; Wang, Y.; Niyyati, M.; Padayatty, S.J.; Head, B.; Wilkins, K.; Chung, S.; Thakur, V.; Ulatowski, L.; et al. Vitamin E sequestration by liver fat in humans. JCI Insight 2020, 5, e133309. [CrossRef]

92. Sanyal, A.J.; Chalasani, N.; Kowdley, K.V.; McCullough, A.; Diehl, A.M.; Bass, N.M.; Neuschwander-Tetri, B.A.; Lavine, J.E.; Tonascia, J.; Unalp, A.; et al. Pioglitazone, vitamin E, or placebo for nonalcoholic steatohepatitis. N. Engl. J. Med. 2010, 362, 1675-1685. [CrossRef] [PubMed]

93. Lavine, J.E. Vitamin E treatment of nonalcoholic steatohepatitis in children: A pilot study. J. Pediatr. 2000, 136, 734-738. [CrossRef]

94. Ford, E.S.; Mokdad, A.H.; Giles, W.H.; Brown, D.W. The metabolic syndrome and antioxidant concentrations: Findings from the Third National Health and Nutrition Examination Survey. Diabetes 2003, 52, 2346-2352. [CrossRef] [PubMed]

95. Beydoun, M.A.; Shroff, M.R.; Chen, X.; Beydoun, H.A.; Wang, Y.; Zonderman, A.B. Serum antioxidant status is associated with metabolic syndrome among U.S. adults in recent national surveys. J. Nutr. 2011, 141, 903-913. [CrossRef] [PubMed]

96. Yen, C.-H.; Yang, N.-C.; Lee, B.-J.; Lin, J.-Y.; Hsia, S.; Lin, P.-T. The antioxidant status and concentrations of coenzyme Q10 and vitamin E in metabolic syndrome. Sci. World J. 2013, 2013, 767968. [CrossRef] [PubMed]

97. Mah, E.; Sapper, T.N.; Chitchumroonchokchai, C.; Failla, M.L.; Schill, K.E.; Clinton, S.K.; Bobe, G.; Traber, M.G.; Bruno, R.S. $\alpha$-Tocopherol bioavailability is lower in adults with metabolic syndrome regardless of dairy fat co-ingestion: A randomized, double-blind, crossover trial. Am. J. Clin. Nutr. 2015, 102, 1070-1080. [CrossRef] [PubMed]

98. Whelton, P.K.; Carey, R.M.; Aronow, W.S.; Casey, D.E.; Collins, K.J.; Dennison, H.C.; DePalma, S.M.; Gidding, S.; Jamerson, K.A.; Jones, D.W.; et al. 2017 ACC/AHA/AAPA/ABC/ACPM/AGS/APhA/ASH/ASPC /NMA/PCNA Guideline for the prevention, detection, evaluation, and management of high blood pressure in adults: A report of the American College of Cardiology/American Heart Association Task Force on Clinical Practice Guidelines. Hypertension 2018, 71, e13-e115. [CrossRef]

99. Emami, M.R.; Safabakhsh, M.; Alizadeh, S.; Asbaghi, O.; Khosroshahi, M.Z. Effect of vitamin E supplementation on blood pressure: A systematic review and meta-analysis. J. Hum. Hypertens. 2019, 33, 499-507. [CrossRef]

100. Hodgson, J.M.; Croft, K.D.; Woodman, R.J.; Puddey, I.B.; Bondonno, C.P.; Wu, J.H.Y.; Beilin, L.J.; Lukoshkova, E.V.; Head, G.A.; Ward, N.C. Effects of vitamin E, vitamin C and polyphenols on the rate of blood pressure variation: Results of two randomised controlled trials. Br. J. Nutr. 2014, 112, 1551-1561. [CrossRef]

101. Mellyana, O.; Widajat, R.; Sekarwana, N. Combined supplementation with $\alpha$-tocopherol and vitamin C improves the blood pressure of pediatric idiopathic nephrotic syndrome patients. Clin. Nutr. Exp. 2019, 23, 116-121. [CrossRef]

102. Sorriento, D.; Luca, N.D.; Trimarco, B.; Iaccarino, G. The antioxidant therapy: New insights in the treatment of hypertension. Front. Physiol. 2018, 9. [CrossRef]

103. Cuevas, S.; Villar, V.A.M.; Jose, P.A. Genetic polymorphisms associated with reactive oxygen species and blood pressure regulation. Pharm. J. 2019, 19, 315-336. [CrossRef]

104. Kizhakekuttu, T.J.; Widlansky, M.E. Natural antioxidants and hypertension: Promise and challenges. Cardiovasc. Ther. 2010, 28, e20-e32. [CrossRef] [PubMed]

105. Gencer, B.; Mach, F. Lipid management in ACS: Should we go lower faster? Atherosclerosis 2018, 275, 368-375. [CrossRef] [PubMed] 
106. Borén, J.; Chapman, M.J.; Krauss, R.M.; Packard, C.J.; Bentzon, J.F.; Binder, C.J.; Daemen, M.J.; Demer, L.L.; Hegele, R.A.; Nicholls, S.J.; et al. Low-density lipoproteins cause atherosclerotic cardiovascular disease: Pathophysiological, genetic, and therapeutic insights: A consensus statement from the European Atherosclerosis Society Consensus Panel. Eur. Heart J. 2020, 41, 2313-2330. [CrossRef] [PubMed]

107. Grundy, S.M.; Stone, N.J.; Bailey, A.L.; Beam, C.; Birtcher, K.K.; Blumenthal, R.S.; Braun, L.T.; de Ferranti, S.; Faiella-Tommasino, J.; Forman, D.E.; et al. 2018 AHA/ACC/AACVPR/AAPA/ABC/ACPM/ADA/AGS/APhA /ASPC/NLA/PCNA Guideline on the Management of blood cholesterol: A report of the American College of Cardiology/American Heart Association Task Force on Clinical Practice Guidelines. J. Am. Coll. Cardiol. 2019, 73, e285-e350. [CrossRef] [PubMed]

108. Galli, F.; Iuliano, L. Do statins cause myopathy by lowering vitamin E levels? Med. Hypotheses 2010, 74, 707-709. [CrossRef]

109. De Caterina, R.; Cipollone, F.; Filardo, F.P.; Zimarino, M.; Bernini, W.; Lazzerini, G.; Bucciarelli, T.; Falco, A.; Marchesani, P.; Muraro, R.; et al. Low-Density Lipoprotein level reduction by the 3-Hydroxy-3-Methylglutaryl Coenzyme-A inhibitor simvastatin is accompanied by a related reduction of $\mathrm{F}_{2}$-Isoprostane formation in hypercholesterolemic subjects: No further effect of vitamin E. Circulation 2002, 106, 2543-2549. [CrossRef]

110. Gotto, A.M. Antioxidants, statins, and atherosclerosis. J. Am. Coll. Cardiol. 2003, 41, 1205-1210. [CrossRef]

111. Qamar, A.; Bhatt, D.L. Effect of low cholesterol on steroid hormones and vitamin E levels: Just a theory or real concern? Circ. Res. 2015, 117, 662-664. [CrossRef]

112. Violi, F.; Cangemi, R. Statin treatment as a confounding factor in human trials with vitamin E. J. Nutr. 2008, 138, 1179-1181. [CrossRef]

113. Traber, M.G. Regulation of xenobiotic metabolism, the only signaling function of alpha-tocopherol? Mol. Nutr. Food Res. 2010, 54, 661-668. [CrossRef]

114. Landes, N.; Pfluger, P.; Kluth, D.; Birringer, M.; Rühl, R.; Böl, G.-F.; Glatt, H.; Brigelius-Flohé, R. Vitamin E activates gene expression via the pregnane $X$ receptor. Biochem. Pharm. 2003, 65, 269-273. [CrossRef]

115. Masuyama, H.; Suwaki, N.; Tateishi, Y.; Nakatsukasa, H.; Segawa, T.; Hiramatsu, Y. The pregnane X receptor regulates gene expression in a ligand- and promoter-selective fashion. Mol. Endocrinol. 2005, 19, 1170-1180. [CrossRef] [PubMed]

116. Lehmann, J.M.; McKee, D.D.; Watson, M.A.; Willson, T.M.; Moore, J.T.; Kliewer, S.A. The human orphan nuclear receptor PXR is activated by compounds that regulate CYP3A4 gene expression and cause drug interactions. J. Clin. Investig. 1998, 102, 1016-1023. [CrossRef] [PubMed]

117. Traber, M.G. Vitamin E and K interactions-a 50-year-old problem. Nutr. Rev. 2008, 66, 624-629. [CrossRef]

118. Ichikawa, T.; Horie-Inoue, K.; Ikeda, K.; Blumberg, B.; Inoue, S. Steroid and xenobiotic receptor SXR mediates vitamin K2-activated transcription of extracellular matrix-related genes and collagen accumulation in osteoblastic cells. J. Biol. Chem. 2006, 281, 16927-16934. [CrossRef]

119. Ikegami, H.; Kawawa, R.; Ichi, I.; Ishikawa, T.; Koike, T.; Aoki, Y.; Fujiwara, Y. Excessive vitamin E intake does not cause bone loss in male or ovariectomized female mice fed normal or high-fat diets. J. Nutr. 2017, 147, 1932-1937. [CrossRef]

120. Booth, S.L.; Golly, I.; Sacheck, J.M.; Roubenoff, R.; Dallal, G.E.; Hamada, K.; Blumberg, J.B. Effect of vitamin E supplementation on vitamin $\mathrm{K}$ status in adults with normal coagulation status. Am. J. Clin. Nutr. 2004, 80, 143-148. [CrossRef]

121. Pastori, D.; Carnevale, R.; Cangemi, R.; Saliola, M.; Nocella, C.; Bartimoccia, S.; Vicario, T.; Farcomeni, A.; Violi, F.; Pignatelli, P. Vitamin E serum levels and bleeding risk in patients receiving oral anticoagulant therapy: A retrospective cohort study. J. Am. Heart Assoc. 2013, 2. [CrossRef]

122. Campbell, D.; Bunker, V.W.; Thomas, A.J.; Clayton, B.E. Selenium and vitamin E status of healthy and institutionalized elderly subjects: Analysis of plasma, erythrocytes and platelets. Br. J. Nutr. 1989, 62, 221-227. [CrossRef]

123. Meydani, S.N.; Han, S.N.; Hamer, D.H. Vitamin E and respiratory infection in the elderly. Ann. N. Y. Acad. Sci. 2004, 1031, 214-222. [CrossRef]

124. Polidori, M.C.; Mecocci, P.; Stahl, W.; Parente, B.; Cecchetti, R.; Cherubini, A.; Cao, P.; Sies, H.; Senin, U. Plasma levels of lipophilic antioxidants in very old patients with type 2 diabetes. Diabetes Metab. Res. Rev. 2000, 16, 15-19. [CrossRef] 
125. Athinarayanan, S.; Wei, R.; Zhang, M.; Bai, S.; Traber, M.G.; Yates, K.; Cummings, O.W.; Molleston, J.; Liu, W.; Chalasani, N. Genetic polymorphism of cytochrome P450 4F2, vitamin E level and histological response in adults and children with nonalcoholic fatty liver disease who participated in PIVENS and TONIC clinical trials. PLoS ONE 2014, 9, e95366. [CrossRef] [PubMed]

126. Meydani, S.N.; Lewis, E.D.; Wu, D. Perspective: Should vitamin E recommendations for older adults be increased? Adv. Nutr. 2018, 9, 533-543. [CrossRef] [PubMed]

127. Meydani, M. Effect of functional food ingredients: Vitamin E modulation of cardiovascular diseases and immune status in the elderly. Am. J. Clin. Nutr. 2000, 71, 1665-1668, discussion 1674S-1675S. [CrossRef] [PubMed]

128. Hales, C.; Carroll, M.; Fryar, C.; Ogden, C. Prevalence of Obesity and Severe Obesity among Adults: United States, 2017-2018; NCHS Data Brief, No 360; National Center for Health Statistics: Hyattsville, MD, USA, 2020.

129. Codoñer-Franch, P.; Pons-Morales, S.; Boix-García, L.; Valls-Bellés, V. Oxidant/antioxidant status in obese children compared to pediatric patients with type 1 diabetes mellitus. Pediatr Diabetes 2010, 11, 251-257. [CrossRef]

130. Mohn, A.; Catino, M.; Capanna, R.; Giannini, C.; Marcovecchio, M.; Chiarelli, F. Increased oxidative stress in prepubertal severely obese children: Effect of a dietary restriction-weight loss program. J. Clin. Endocrinol. Metab. 2005, 90, 2653-2658. [CrossRef]

131. Morinobu, T.; Murata, T.; Takaya, R.; Tamai, H. Nutritional status of beta-carotene, alpha-tocopherol and retinol in obese children. Int. J. Vitam. Nutr. Res. 2002, 72, 119-123. [CrossRef]

132. Switzer, B.R.; Atwood, J.R.; Stark, A.H.; Hatch, J.W.; Travis, R.; Ullrich, F.; Lyden, E.R.; Wu, X.; Chiu, Y.; Smith, J.L. Plasma carotenoid and vitamins a and e concentrations in older African American women after wheat bran supplementation: Effects of age, body mass and smoking history. J. Am. Coll. Nutr. 2005, 24, 217-226. [CrossRef]

133. Verrotti, A.; Greco, R.; Latini, G.; De Simone, M.; Chiarelli, F. Obesity and plasma concentrations of alpha-tocopherol and beta-carotene in epileptic girls treated with valproate. Neuroendocrinology 2004, 79, 157-162. [CrossRef]

134. Guerendiain, M.; Mayneris-Perxachs, J.; Montes, R.; López-Belmonte, G.; Martín-Matillas, M.; Castellote, A.I.; Martín-Bautista, E.; Martí, A.; Martínez, J.A.; Moreno, L.; et al. Relation between plasma antioxidant vitamin levels, adiposity and cardio-metabolic profile in adolescents: Effects of a multidisciplinary obesity programme. Clin. Nutr 2017, 36, 209-217. [CrossRef]

135. Voegele, A.F.; Jerković, L.; Wellenzohn, B.; Eller, P.; Kronenberg, F.; Liedl, K.R.; Dieplinger, H. Characterization of the vitamin E-binding properties of human plasma afamin. Biochemistry 2002, 41, 14532-14538. [CrossRef] [PubMed]

136. Salonen, J.T.; Nyyssönen, K.; Tuomainen, T.P.; Mäenpää, P.H.; Korpela, H.; Kaplan, G.A.; Lynch, J.; Helmrich, S.P.; Salonen, R. Increased risk of non-insulin dependent diabetes mellitus at low plasma vitamin E concentrations: A four year follow up study in men. BMJ 1995, 311, 1124-1127. [CrossRef] [PubMed]

137. Upritchard, J.E.; Sutherland, W.H.; Mann, J.I. Effect of supplementation with tomato juice, vitamin E, and vitamin C on LDL oxidation and products of inflammatory activity in type 2 diabetes. Diabetes Care 2000, 23, 733-738. [CrossRef]

138. Devaraj, S.; Jialal, I. Alpha tocopherol supplementation decreases serum C-reactive protein and monocyte interleukin-6 levels in normal volunteers and type 2 diabetic patients. Free Radic. Biol. Med. 2000, 29, 790-792. [CrossRef]

139. Szanto, K.; Li, J.; Cordero, P.; Oben, J. Ethnic differences and heterogeneity in genetic and metabolic makeup contributing to nonalcoholic fatty liver disease. DMSO 2019, 12, 357-367. [CrossRef] [PubMed]

140. Yamada, S.; Kamada, N.; Amiya, T.; Nakamoto, N.; Nakaoka, T.; Kimura, M.; Saito, Y.; Ejima, C.; Kanai, T.; Saito, H. Gut microbiota-mediated generation of saturated fatty acids elicits inflammation in the liver in murine high-fat diet-induced steatohepatitis. BMC Gastroenterol. 2017, 17, 136. [CrossRef]

141. Henao-Mejia, J.; Elinav, E.; Jin, C.; Hao, L.; Mehal, W.Z.; Strowig, T.; Thaiss, C.A.; Kau, A.L.; Eisenbarth, S.C.; Jurczak, M.J.; et al. Inflammasome-mediated dysbiosis regulates progression of NAFLD and obesity. Nature 2012, 482, 179-185. [CrossRef]

142. Jie, Z.; Xia, H.; Zhong, S.-L.; Feng, Q.; Li, S.; Liang, S.; Zhong, H.; Liu, Z.; Gao, Y.; Zhao, H.; et al. The gut microbiome in atherosclerotic cardiovascular disease. Nat. Commun. 2017, 8, 845. [CrossRef] 
143. Barrington, W.T.; Lusis, A.J. Atherosclerosis: Association between the gut microbiome and atherosclerosis. Nat. Rev. Cardiol. 2017, 14, 699-700. [CrossRef]

144. Wallert, M.; Börmel, L.; Lorkowski, S. Inflammatory diseases andvitamin E - what do we know and where do we go? Mol. Nutr Food Res. 2020, e2000097. [CrossRef]

145. Adams, L.A.; Anstee, Q.M.; Tilg, H.; Targher, G. Non-alcoholic fatty liver disease and its relationship with cardiovascular disease and other extrahepatic diseases. Gut 2017, 66, 1138-1153. [CrossRef]

146. Expert panel on detection, evaluation, and treatment of high blood cholesterol in adults executive summary of the third report of the National Cholesterol Education Program (NCEP) expert panel on detection, evaluation, and treatment of high blood cholesterol in adults (Adult Treatment Panel III). JAMA J. Am. Med. Assoc. 2001, 285, 2486-2497. [CrossRef]

147. Godala, M.; Materek-Kuśmierkiewicz, I.; Moczulski, D.; Rutkowski, M.; Szatko, F.; Gaszyńska, E.; Tokarski, S.; Kowalski, J. The risk of plasma vitamin A, C, E and D deficiency in patients with metabolic syndrome: A case-control study. Adv. Clin. Exp. Med. 2017, 26, 581-586. [CrossRef] [PubMed]

148. Kitagawa, A.; Ohta, Y.; Ohashi, K.; Yashiro, K.; Fukuzawa, K. Effect of high fructose-induced metabolic syndrome on tissue vitamin E and lipid peroxide levels in rats. J. Nutr. Sci. Vitam. 2020, 66, 200-206. [CrossRef] [PubMed]

149. Traber, M.G.; Mah, E.; Leonard, S.W.; Bobe, G.; Bruno, R.S. Metabolic syndrome increases dietary $\alpha$-tocopherol requirements as assessed using urinary and plasma vitamin E catabolites: A double-blind, crossover clinical trial. Am. J. Clin. Nutr. 2017, 105, 571-579. [CrossRef]

150. Wong, S.K.; Chin, K.-Y.; Suhaimi, F.H.; Ahmad, F.; Ima-Nirwana, S. The Effects of Vitamin E from Elaeis guineensis (Oil Palm) in a rat model of bone loss due to metabolic syndrome. Int. J. Environ. Res. Public Health 2018, 15, 1828. [CrossRef]

151. Czernichow, S.; Vergnaud, A.-C.; Galan, P.; Arnaud, J.; Favier, A.; Faure, H.; Huxley, R.; Hercberg, S.; Ahluwalia, N. Effects of long-term antioxidant supplementation and association of serum antioxidant concentrations with risk of metabolic syndrome in adults. Am. J. Clin. Nutr. 2009, 90, 329-335. [CrossRef]

152. Gey, K.F.; Puska, P.; Jordan, P.; Moser, U.K. Inverse correlation between plasma vitamin E and mortality from ischemic heart disease in cross-cultural epidemiology. Am. J. Clin. Nutr. 1991, 53, 326S-334S. [CrossRef]

153. Riemersma, R.A.; Wood, D.A.; Macintyre, C.C.; Elton, R.A.; Gey, K.F.; Oliver, M.F. Risk of angina pectoris and plasma concentrations of vitamins A, C, and E and carotene. Lancet 1991, 337, 1-5. [CrossRef]

154. Huang, J.; Weinstein, S.J.; Yu, K.; Männistö, S.; Albanes, D. Relationship between serum alpha-tocopherol and overall and cause-specific mortality. Circ. Res. 2019, 125, 29-40. [CrossRef]

155. Rimm, E.B.; Stampfer, M.J.; Ascherio, A.; Giovannucci, E.; Colditz, G.A.; Willett, W.C. Vitamin E Consumption and the Risk of Coronary Heart Disease in Men. Available online: https://www.nejm.org/doi/10.1056/NEJM199305203282004? url_ver=Z39.88-2003\&rfr_id=ori\%3Arid\%3Acrossref.org\&rfr_dat=cr_pub++0www.ncbi.nlm.nih.gov (accessed on 30 June 2020).

156. Bolton-Smith, C.; Woodward, M.; Tunstall-Pedoe, H. The Scottish Heart Health Study. Dietary intake by food frequency questionnaire and odds ratios for coronary heart disease risk. II. The antioxidant vitamins and fibre. Eur. J. Clin. Nutr 1992, 46, 85-93. [PubMed]

157. Knekt, P.; Reunanen, A.; Jävinen, R.; Seppänen, R.; Heliövaara, M.; Aromaa, A. Antioxidant vitamin intake and coronary mortality in a longitudinal population study. Am. J. Epidemiol. 1994, 139, 1180-1189. [CrossRef] [PubMed]

158. Kushi, L.H.; Folsom, A.R.; Prineas, R.J.; Mink, P.J.; Wu, Y.; Bostick, R.M. Dietary Antioxidant Vitamins and Death from Coronary Heart Disease in Postmenopausal Women. Available online: https://www.nejm.org/doi/10.1056/NEJM199605023341803?url_ver=Z39.88-2003\&rfr_id=ori\%3Arid\%3Acrossref. org\&rfr_dat=cr_pub++0www.ncbi.nlm.nih.gov (accessed on 30 June 2020).

159. Meyer, F.; Bairati, I.; Dagenais, G.R. Lower ischemic heart disease incidence and mortality among vitamin supplement users. Can. J. Cardiol. 1996, 12, 930-934. [PubMed]

160. Losonczy, K.G.; Harris, T.B.; Havlik, R.J. Vitamin E and vitamin C supplement use and risk of all-cause and coronary heart disease mortality in older persons: The Established Populations for Epidemiologic Studies of the Elderly. Am. J. Clin. Nutr. 1996, 64, 190-196. [CrossRef] [PubMed]

161. Stampfer, M.J.; Hennekens, C.H.; Manson, J.E.; Colditz, G.A.; Rosner, B.; Willett, W.C. Vitamin EConsumption and the Risk Of Coronary Disease in Women. Available online: https://www.nejm.org/doi/10.1056/NEJM199305203282003? url_ver=Z39.88-2003\&rfr_id=ori\%3Arid\%3Acrossref.org\&rfr_dat=cr_pub++0www.ncbi.nlm.nih.gov (accessed on 1 July 2020). 
162. Lee, C.-H.; Chan, R.S.M.; Wan, H.Y.L.; Woo, Y.-C.; Cheung, C.Y.Y.; Fong, C.H.Y.; Cheung, B.M.Y.; Lam, T.-H.; Janus, E.; Woo, J.; et al. Dietary intake of anti-oxidant vitamins A, C, and E is inversely associated with adverse cardiovascular outcomes in chinese-A 22-years population-based prospective study. Nutrients 2018, 10, 1664. [CrossRef]

163. Wang, T.; Xu, L. Circulating vitamin E levels and risk of coronary artery disease and myocardial infarction: A mendelian randomization study. Nutrients 2019, 11, 2153. [CrossRef]

164. Hak, A.E.; Stampfer, M.J.; Campos, H.; Sesso, H.D.; Gaziano, J.M.; Willett, W.; Ma, J. Plasma Carotenoids and tocopherols and risk of myocardial infarction in a low-risk population of US male physicians. Circulation 2003, 108, 802-807. [CrossRef]

165. Hense, H.W.; Stender, M.; Borsc, W.; Keil, U. Lack of an association between serum vitamin E and myocardial infarction in a population with high vitamin E levels. Atherosclerosis 1993, 103, 21-28. [CrossRef]

166. Bashar, T.; Akhter, N. Oxidative stress and antioxidant status in patients of acute myocardial infarction before and after regular treatment. Univ. Heart J. 2014, 10, 60-65. [CrossRef]

167. Scragg, R.; Jackson, R.; Holdaway, I.; Woollard, G.; Woollard, D. Changes in plasma vitamin levels in the first $48 \mathrm{~h}$ after onset of acute myocardial infarction. Am. J. Cardiol. 1989, 64, 971-974. [CrossRef]

168. Labadarios, D.; Brink, P.A.; Weich, H.F.; Visser, L.; Louw, M.E.; Shephard, G.S.; van Stuijvenberg, M.E. Plasma vitamin A, E, C and B6 levels in myocardial infarction. S. Afr. Med. J. 1987, 71, 561-563. [PubMed]

169. Sood, R.; Narang, A.P.S.; Abraham, R.; Arora, U.; Calton, R.; Sood, N. Changes in vitamin C and vitamin E during oxidative stress in myocardial reperfusion. Indian J. Physiol. Pharm. 2007, 51, 165-169.

170. Ricciarelli, R.; Zingg, J.M.; Azzi, A. Vitamin E: Protective role of a Janus molecule. FASEB J. 2001, 15, $2314-2325$. [CrossRef]

171. Nègre-Salvayre, A.; Mabile, L.; Delchambre, J.; Salvayre, R. alpha-Tocopherol, ascorbic acid, and rutin inhibit synergistically the copper-promoted LDL oxidation and the cytotoxicity of oxidized LDL to cultured endothelial cells. Biol Trace Elem. Res. 1995, 47, 81-91. [CrossRef] [PubMed]

172. Villacorta, L.; Azzi, A.; Zingg, J.-M. Regulatory role of vitamins E and C on extracellular matrix components of the vascular system. Mol. Asp. Med. 2007, 28, 507-537. [CrossRef] [PubMed]

173. Ricciarelli, R.; Maroni, P.; Özer, N.; Zingg, J.-M.; Azzi, A. Age-dependent increase of collagenase expression can be reduced by $\alpha$-tocopherol via protein kinase C inhibition. Free Radic. Biol. Med. 1999, 27, $729-737$. [CrossRef]

174. Boscoboinik, D.; Szewczyk, A.; Hensey, C.; Azzi, A. Inhibition of cell proliferation by alpha-tocopherol. Role of protein kinase C. J. Biol. Chem. 1991, 266, 6188-6194.

175. Mahoney, C.W.; Azzi, A. Vitamin E inhibits protein kinase C activity. Biochem. Biophys. Res. Commun. 1988, 154, 694-697. [CrossRef]

176. Tasinato, A.; Boscoboinik, D.; Bartoli, G.M.; Maroni, P.; Azzi, A. d-alpha-tocopherol inhibition of vascular smooth muscle cell proliferation occurs at physiological concentrations, correlates with protein kinase C inhibition, and is independent of its antioxidant properties. Proc. Natl. Acad. Sci. USA 1995, 92, 12190-12194. [CrossRef]

177. Devaraj, S.; Jialal, I. The effects of alpha-tocopherol on critical cells in atherogenesis. Curr. Opin. Lipidol. 1998, 9, 11-15. [CrossRef]

178. Cominacini, L.; Garbin, U.; Pasini, A.F.; Davoli, A.; Campagnola, M.; Contessi, G.B.; Pastorino, A.M.; Lo Cascio, V. Antioxidants inhibit the expression of intercellular cell adhesion molecule-1 and vascular cell adhesion molecule-1 induced by oxidized LDL on human umbilical vein endothelial cells. Free Radic. Biol. Med. 1997, 22, 117-127. [CrossRef]

179. van Dam, B.; van Hinsbergh, V.W.M.; Stehouwer, C.D.A.; Versteilen, A.; Dekker, H.; Buytenhek, R.; Princen, H.M.; Schalkwijk, C.G. Vitamin E inhibits lipid peroxidation-induced adhesion molecule expression in endothelial cells and decreases soluble cell adhesion molecules in healthy subjects. Cardiovasc. Res. 2003, 57, 563-571. [CrossRef]

180. Koga, T.; Kwan, P.; Zubik, L.; Ameho, C.; Smith, D.; Meydani, M. Vitamin E supplementation suppresses macrophage accumulation and endothelial cell expression of adhesion molecules in the aorta of hypercholesterolemic rabbits. Atherosclerosis 2004, 176, 265-272. [CrossRef] [PubMed]

181. Koga, T.; Claycombe, K.; Meydani, M. Homocysteine increases monocyte and T-cell adhesion to human aortic endothelial cells. Atherosclerosis 2002, 161,365-374. [CrossRef] 
182. Orbe, J.; Rodríguez, J.A.; Arias, R.; Belzunce, M.; Nespereira, B.; Pérez-Ilzarbe, M.; Roncal, C.; Páramo, J.A. Antioxidant vitamins increase the collagen content and reduce MMP-1 in a porcine model of atherosclerosis: Implications for plaque stabilization. Atherosclerosis 2003, 167, 45-53. [CrossRef]

183. Schwenke, D.C.; Rudel, L.L.; Sorci-Thomas, M.G.; Thomas, M.J. $\alpha$-Tocopherol protects against diet induced atherosclerosis in New Zealand white rabbits. J. Lipid Res. 2002, 43, 1927-1938. [CrossRef]

184. Hodis, H.N.; Mack, W.J.; LaBree, L.; Mahrer, P.R.; Sevanian, A.; Liu, C.-R.; Liu, C.-H.; Hwang, J.; Selzer, R.H.; Azen, S.P. Alpha-tocopherol supplementation in healthy individuals reduces low-density lipoprotein oxidation but not atherosclerosis. Circulation 2002, 106, 1453-1459. [CrossRef]

185. McQuillan, B.M.; Hung, J.; Beilby, J.P.; Nidorf, M.; Thompson, P.L. Antioxidant vitamins and the risk of carotid atherosclerosis: The perth carotid ultrasound disease assessment study (CUDAS). J. Am. Coll. Cardiol. 2001, 38, 1788-1794. [CrossRef]

186. Magliano, D.; McNeil, J.; Branley, P.; Shiel, L.; Demos, L.; Wolfe, R.; Kotsopoulos, D.; McGrath, B. The Melbourne Atherosclerosis Vitamin E Trial (MAVET): A study of high dose vitamin E in smokers. Eur. J. Cardiovasc. Prev. Rehabil. 2006, 13, 341-347. [CrossRef]

187. Devaraj, S.; Tang, R.; Adams-Huet, B.; Harris, A.; Seenivasan, T.; de Lemos, J.A.; Jialal, I. Effect of high-dose $\alpha$-tocopherol supplementation on biomarkers of oxidative stress and inflammation and carotid atherosclerosis in patients with coronary artery disease. Am. J. Clin. Nutr. 2007, 86, 1392-1398. [CrossRef]

188. Lonn, E.M.; Yusuf, S.; Dzavik, V.; Doris, C.I.; Yi, Q.; Smith, S.; Moore-Cox, A.; Bosch, J.; Riley, W.A.; Teo, K.K. Effects of ramipril and vitamin E on atherosclerosis. Circulation 2001, 103, 919-925. [CrossRef] [PubMed]

189. Rapola, J.M.; Virtamo, J.; Haukka, J.K.; Heinonen, O.P.; Albanes, D.; Taylor, P.R.; Huttunen, J.K. Effect of vitamin $\mathrm{E}$ and beta carotene on the incidence of angina pectoris: A randomized, double-blind, controlled trial. JAMA 1996, 275, 693-698. [CrossRef] [PubMed]

190. de Gaetano, G.; Collaborative Group of the Primary Prevention Project. Low-dose aspirin and vitamin E in people at cardiovascular risk: A randomised trial in general practice. Collaborative Group of the Primary Prevention Project. Lancet 2001, 357, 89-95. [PubMed]

191. Stephens, N.G.; Parsons, A.; Schofield, P.M.; Kelly, F.; Cheeseman, K.; Mitchinson, M.J. Randomised controlled trial of vitamin $\mathrm{E}$ in patients with coronary disease: Cambridge Heart Antioxidant Study (CHAOS). Lancet 1996, 347, 781-786. [CrossRef]

192. Boaz, M.; Smetana, S.; Weinstein, T.; Matas, Z.; Gafter, U.; Iaina, A.; Knecht, A.; Weissgarten, Y.; Brunner, D.; Fainaru, M.; et al. Secondary prevention with antioxidants of cardiovascular disease in endstage renal disease (SPACE): Randomised placebo-controlled trial. Lancet 2000, 356, 1213-1218. [CrossRef]

193. Marchioli, R. Treatment with n-3 polyunsaturated fatty acids after myocardial infarction: Results of GISSI-prevenzione trial. Eur. Heart J. Suppl. 2001, 3, D85-D97. [CrossRef]

194. Alkhenizan, A.H.; Al-Omran, M.A. The role of vitamin $\mathrm{E}$ in the prevention of coronary events and stroke. Meta-analysis of randomized controlled trials. Neurosciences (Riyadh) 2005, 10, 23-29.

195. Wallert, M.; Ziegler, M.; Wang, X.; Maluenda, A.; Xu, X.; Yap, M.L.; Witt, R.; Giles, C.; Kluge, S.; Hortmann, M.; et al. $\alpha$-Tocopherol preserves cardiac function by reducing oxidative stress and inflammation in ischemia/reperfusion injury. Redox Biol. 2019, 26, 101292. [CrossRef]

196. Saleh, N.K.; Saleh, H.A. Protective effects of vitamin E against myocardial ischemia/reperfusion injury in rats. Saudi Med. J. 2010, 31, 142-147.

197. Tripathi, Y.; Hegde, B.M. Effect of alpha-tocopherol pretreatment on infarct size following 90 min of ischemia and $4 \mathrm{~h}$ of reperfusion in dogs. Indian J. Physiol. Pharm. 1997, 41, 241-247.

198. Sethi, R.; Takeda, N.; Nagano, M.; Dhalla, N.S. Beneficial effects of vitamin E treatment in acute myocardial infarction. J. Cardiovasc. Pharmacol. Ther. 2016. [CrossRef] [PubMed]

199. Jaxa-Chamiec, T.; Bednarz, B.; Drozdowska, D.; Gessek, J.; Gniot, J.; Janik, K.; Kawka-Urbanek, T.; Maciejewski, P.; Ogórek, M.; Szpajer, M.; et al. Antioxidant effects of combined vitamins C and E in acute myocardial infarction. The randomized, double-blind, placebo controlled, multicenter pilot Myocardial Infarction and VITamins (MIVIT) trial. Kardiol. Pol. 2005, 62, 344-350. [PubMed]

200. Singh, R.B.; Niaz, M.A.; Rastogi, S.S.; Rastogi, S. Usefulness of antioxidant vitamins in suspected acute myocardial infarction (the Indian experiment of infarct survival-3). Am. J. Cardiol. 1996, 77, 232-236. [CrossRef]

201. Wallert, M.; Schmölz, L.; Galli, F.; Birringer, M.; Lorkowski, S. Regulatory metabolites of vitamin E and their putative relevance for atherogenesis. Redox Biol. 2014, 2, 495-503. [CrossRef] [PubMed] 
202. Döring, F.; Rimbach, G.; Lodge, J. In Silico Search for Single Nucleotide Polymorphisms in Genes Important in Vitamin E Homeostasis. IUBMB Life (Int. Union Biochem. Mol. Biol. Life) 2004, 56, 615-620. [CrossRef]

203. Christen, S.; Woodall, A.A.; Shigenaga, M.K.; Southwell-Keely, P.T.; Duncan, M.W.; Ames, B.N. gamma-tocopherol traps mutagenic electrophiles such as $\mathrm{NO}(\mathrm{X})$ and complements alpha-tocopherol: Physiological implications. Proc. Natl. Acad. Sci. USA 1997, 94, 3217-3222. [CrossRef]

204. Devaraj, S.; Leonard, S.; Traber, M.G.; Jialal, I. Gamma-tocopherol supplementation alone and in combination with alpha-tocopherol alters biomarkers of oxidative stress and inflammation in subjects with metabolic syndrome. Free Radic. Biol. Med. 2008, 44, 1203-1208. [CrossRef]

205. Himmelfarb, J.; Kane, J.; McMonagle, E.; Zaltas, E.; Bobzin, S.; Boddupalli, S.; Phinney, S.; Miller, G. Alpha and gamma tocopherol metabolism in healthy subjects and patients with end-stage renal disease. Kidney Int. 2003, 64, 978-991. [CrossRef]

206. Smith, K.S.; Lee, C.-L.; Ridlington, J.W.; Leonard, S.W.; Devaraj, S.; Traber, M.G. Vitamin E supplementation increases circulating vitamin E metabolites tenfold in end-stage renal disease patients. Lipids 2003, 38, 813-819. [CrossRef]

207. Wu, J.H.Y.; Ward, N.C.; Indrawan, A.P.; Almeida, C.-A.; Hodgson, J.M.; Proudfoot, J.M.; Puddey, I.B.; Croft, K.D. Effects of alpha-tocopherol and mixed tocopherol supplementation on markers of oxidative stress and inflammation in type 2 diabetes. Clin. Chem. 2007, 53, 511-519. [CrossRef]

208. Ward, N.C.; Wu, J.H.; Clarke, M.W.; Puddey, I.B.; Burke, V.; Croft, K.D.; Hodgson, J.M. The effect of vitamin E on blood pressure in individuals with type 2 diabetes: A randomized, double-blind, placebo-controlled trial. J. Hypertens. 2007, 25, 227-234. [CrossRef] [PubMed]

209. Mathur, P.; Ding, Z.; Saldeen, T.; Mehta, J.L. Tocopherols in the prevention and treatment of atherosclerosis and related cardiovascular disease. Clin. Cardiol 2015, 38, 570-576. [CrossRef] [PubMed]

210. Jiang, Q. Natural forms of vitamin E: Metabolism, antioxidant, and anti-inflammatory activities and their role in disease prevention and therapy. Free Radic. Biol. Med. 2014, 72, 76-90. [CrossRef] [PubMed]

211. Qureshi, A.A.; Qureshi, N.; Wright, J.J.K.; Shen, Z.; Kramer, G.; Gapor, A.; Chong, Y.H.; DeWitt, G.; Ong, A.S.H.; Peterson, D.M.; et al. Lowering of serum cholesterol in hypercholesterolemic humans by tocotrienols (palmvitee). Am. J. Clin. Nutr. 1991, 53, 1021S-1026S. [CrossRef]

212. Qureshi, A.A.; Bradlow, B.A.; Brace, L.; Manganello, J.; Peterson, D.M.; Pearce, B.C.; Wright, J.J.; Gapor, A.; Elson, C.E. Response of hypercholesterolemic subjects to administration of tocotrienols. Lipids 1995, 30, 1171-1177. [CrossRef]

213. Yuen, K.H.; Wong, J.W.; Lim, A.B.; Ng, B.H.; Choy, W.P. Effect of Mixed-Tocotrienols in Hypercholesterolemic Subjects. FFHD 2011, 1, 106. [CrossRef]

214. Rasool, A.H.G.; Rahman, A.R.A.; Yuen, K.H.; Wong, A.R. Arterial compliance and vitamin E blood levels with a self emulsifying preparation of tocotrienol rich vitamin E. Arch. Pharm. Res. 2008, 31, 1212-1217. [CrossRef]

215. Wallert, M.; Kluge, S.; Schubert, M.; Koeberle, A.; Werz, O.; Birringer, M.; Lorkowski, S. Diversity of chromanol and chromenol structures and functions: An emerging class of anti-inflammatory and anti-carcinogenic agents. Front. Pharm. 2020, 11, 362. [CrossRef]

216. Birringer, M.; Siems, K.; Maxones, A.; Frank, J.; Lorkowski, S. Natural 6-hydroxy-chromanols and -chromenols: Structural diversity, biosynthetic pathways and health implications. RSC Adv. 2018, 8, 4803-4841. [CrossRef]

217. Wallert, M.; Schmölz, L.; Koeberle, A.; Krauth, V.; Glei, M.; Galli, F.; Werz, O.; Birringer, M.; Lorkowski, S. $\alpha$-Tocopherol long-chain metabolite $\alpha-13^{\prime}-\mathrm{COOH}$ affects the inflammatory response of lipopolysaccharide-activated murine RAW264.7 macrophages. Mol. Nutr. Food Res. 2015, 59, 1524-1534. [CrossRef]

218. Ciffolilli, S.; Wallert, M.; Bartolini, D.; Krauth, V.; Werz, O.; Piroddi, M.; Sebastiani, B.; Torquato, P.; Lorkowski, S.; Birringer, M.; et al. Human serum determination and in vitro anti-inflammatory activity of the vitamin E metabolite $\alpha$-(13'-hydroxy)-6-hydroxychroman. Free Radic. Biol. Med. 2015, 89, 952-962. [CrossRef] [PubMed]

219. Wallert, M.; Bauer, J.; Kluge, S.; Schmölz, L.; Chen, Y.-C.; Ziegler, M.; Searle, A.K.; Maxones, A.; Schubert, M.; Thürmer, M.; et al. The vitamin E derivative garcinoic acid from Garcinia kola nut seeds attenuates the inflammatory response. Redox Biol. 2019, 24, 101166. [CrossRef] [PubMed] 
220. Pein, H.; Ville, A.; Pace, S.; Temml, V.; Garscha, U.; Raasch, M.; Alsabil, K.; Viault, G.; Dinh, C.-P.; Guilet, D.; et al. Endogenous metabolites of vitamin $\mathrm{E}$ limit inflammation by targeting 5-lipoxygenase. Nat. Commun. 2018, 9. [CrossRef] [PubMed]

221. Wallert, M.; Mosig, S.; Rennert, K.; Funke, H.; Ristow, M.; Pellegrino, R.M.; Cruciani, G.; Galli, F.; Lorkowski, S.; Birringer, M. Long-chain metabolites of $\alpha$-tocopherol occur in human serum and inhibit macrophage foam cell formation in vitro. Free Radic. Biol. Med. 2014, 68, 43-51. [CrossRef] [PubMed]

222. Schmölz, L.; Schubert, M.; Kirschner, J.; Kluge, S.; Galli, F.; Birringer, M.; Wallert, M.; Lorkowski, S. Long-chain metabolites of vitamin E: Interference with lipotoxicity via lipid droplet associated protein PLIN2. Biochim. Biophys. Acta Mol. Cell Biol. Lipids 2018, 1863, 919-927. [CrossRef] [PubMed]

223. Birringer, M.; Lorkowski, S. Vitamin E: Regulatory role of metabolites: Vitamin E Metabolites. IUBMB Life 2019, 71, 479-486. [CrossRef]

224. Mangan, M.S.J.; Olhava, E.J.; Roush, W.R.; Seidel, H.M.; Glick, G.D.; Latz, E. Targeting the NLRP3 inflammasome in inflammatory diseases. Nat. Rev. Drug Discov. 2018. [CrossRef]

225. Ridker, P.M.; Everett, B.M.; Thuren, T.; MacFadyen, J.G.; Chang, W.H.; Ballantyne, C.; Fonseca, F.; Nicolau, J.; Koenig, W.; Anker, S.D.; et al. Antiinflammatory therapy with canakinumab for atherosclerotic disease. N. Engl. J. Med. 2017, 377, 1119-1131. [CrossRef]

226. Ridker, P.M. High-sensitivity c-reactive protein: Potential adjunct for global risk assessment in the primary prevention of cardiovascular disease. Circulation 2001, 103, 1813-1818. [CrossRef]

227. Ridker, P.M.; MacFadyen, J.G.; Thuren, T.; Libby, P. Residual inflammatory risk associated with interleukin-18 and interleukin- 6 after successful interleukin- $1 \beta$ inhibition with canakinumab: Further rationale for the development of targeted anti-cytokine therapies for the treatment of atherothrombosis. Eur. Heart J. 2020, 41, 2153-2163. [CrossRef]

228. Bedoui, Y.; Guillot, X.; Sélambarom, J.; Guiraud, P.; Giry, C.; Jaffar-Bandjee, M.C.; Ralandison, S.; Gasque, P. Methotrexate an old drug with new tricks. Int. J. Mol. Sci 2019, 20, 5023. [CrossRef] [PubMed]

229. Westlake, S.L.; Colebatch, A.N.; Baird, J.; Kiely, P.; Quinn, M.; Choy, E.; Ostor, A.J.K.; Edwards, C.J. The effect of methotrexate on cardiovascular disease in patients with rheumatoid arthritis: A systematic literature review. Rheumatology 2010, 49, 295-307. [CrossRef]

230. Micha, R.; Imamura, F.; Wyler von Ballmoos, M.; Solomon, D.H.; Hernán, M.A.; Ridker, P.M.; Mozaffarian, D. Systematic review and meta-analysis of methotrexate use and risk of cardiovascular disease. Am. J. Cardiol. 2011, 108, 1362-1370. [CrossRef]

231. Ridker, P.M.; Everett, B.M.; Pradhan, A.; MacFadyen, J.G.; Solomon, D.H.; Zaharris, E.; Mam, V.; Hasan, A.; Rosenberg, Y.; Iturriaga, E.; et al. Low-dose methotrexate for the prevention of atherosclerotic events. N. Engl. J. Med. 2019, 380, 752-762. [CrossRef] [PubMed]

232. Pope, R.M.; Tschopp, J. The role of interleukin-1 and the inflammasome in gout: Implications for therapy. Arthritis Rheum. 2007, 56, 3183-3188. [CrossRef] [PubMed]

233. Nidorf, S.M.; Thompson, P.L. Why colchicine should be considered for secondary prevention of atherosclerosis: An overview. Clin. Ther. 2019, 41, 41-48. [CrossRef]

234. Nidorf, S.M.; Eikelboom, J.W.; Budgeon, C.A.; Thompson, P.L. Low-dose colchicine for secondary prevention of cardiovascular disease. J. Am. Coll. Cardiol. 2013, 61, 404-410. [CrossRef]

235. Tardif, J.-C.; Kouz, S.; Waters, D.D.; Bertrand, O.F.; Diaz, R.; Maggioni, A.P.; Pinto, F.J.; Ibrahim, R.; Gamra, H.; Kiwan, G.S.; et al. Efficacy and safety of low-dose colchicine after myocardial infarction. N. Engl. J. Med. 2019, 381, 2497-2505. [CrossRef]

236. Melamed-Frank, M.; Lache, O.; Enav, B.I.; Szafranek, T.; Levy, N.S.; Ricklis, R.M.; Levy, A.P. Structure-function analysis of the antioxidant properties of haptoglobin. Blood 2001, 98, 3693-3698. [CrossRef]

237. Beeri, M.S.; Lin, H.-M.; Sano, M.; Ravona-Springer, R.; Liu, X.; Bendlin, B.B.; Gleason, C.E.; Guerrero-Berroa, E.; Soleimani, L.; Launer, L.J.; et al. Association of the haptoglobin gene polymorphism with cognitive function and decline in elderly African American adults with type 2 diabetes: Findings from the Action to Control Cardiovascular Risk in Diabetes-Memory in Diabetes (ACCORD-MIND) Study. JAMA Netw. Open 2018, 1, e184458. [CrossRef]

238. Dalan, R.; Liew, H.; Goh, L.L.; Gao, X.; Chew, D.E.; Boehm, B.O.; Leow, M.K.S. The haptoglobin 2-2 genotype is associated with inflammation and carotid artery intima-media thickness. Diab. Vasc. Dis. Res. 2016, 13, 373-376. [CrossRef] [PubMed] 
239. Levy, A.P.; Hochberg, I.; Jablonski, K.; Resnick, H.E.; Lee, E.T.; Best, L.; Howard, B.V. Haptoglobin phenotype is an independent risk factor for cardiovascular disease in individuals with diabetes. J. Am. Coll. Cardiol. 2002, 40, 1984-1990. [CrossRef]

240. Adams, J.N.; Cox, A.J.; Freedman, B.I.; Langefeld, C.D.; Carr, J.J.; Bowden, D.W. Genetic analysis of haptoglobin polymorphisms with cardiovascular disease and type 2 diabetes in the Diabetes Heart Study. Cardiovasc. Diabetol. 2013, 12, 31. [CrossRef] [PubMed]

241. De Bacquer, D.; De Backer, G.; Langlois, M.; Delanghe, J.; Kesteloot, H.; Kornitzer, M. Haptoglobin polymorphism as a risk factor for coronary heart disease mortality. Atherosclerosis 2001, 157, 161-166. [CrossRef]

242. Orchard, T.J.; Backlund, J.-Y.C.; Costacou, T.; Cleary, P.; Lopes-Virella, M.; Levy, A.P.; Lachin, J.M. DCCT/EDIC Research Group Haptoglobin 2-2 genotype and the risk of coronary artery disease in the Diabetes Control and Complications Trial/Epidemiology of Diabetes Interventions and Complications study (DCCT/EDIC). J. Diabetes Complicat. 2016, 30, 1577-1584. [CrossRef] [PubMed]

243. Blum, S.; Vardi, M.; Brown, J.B.; Russell, A.; Milman, U.; Shapira, C.; Levy, N.S.; Miller-Lotan, R.; Asleh, R.; Levy, A.P. Vitamin E reduces cardiovascular disease in individuals with diabetes mellitus and the haptoglobin 2-2 genotype. Pharmacogenomics 2010, 11, 675-684. [CrossRef]

244. Vardi, M.; Blum, S.; Levy, A.P. Haptoglobin genotype and cardiovascular outcomes in diabetes mellitus-Natural history of the disease and the effect of vitamin E treatment. Meta-analysis of the medical literature. Eur. J. Intern. Med. 2012, 23, 628-632. [CrossRef]

245. Asleh, R.; Briasoulis, A.; Berinstein, E.; Wiener, J.; Palla, M.; Kushwaha, S.; Levy, A. Meta-analysis of the association of the haptoglobin genotype with cardiovascular outcomes and the pharmacogenomic interactions with vitamin E supplementation. PGPM 2018, 11, 71-82. [CrossRef]

246. Belitskaya-Lévy, I.; Dysken, M.; Guarino, P.; Sano, M.; Asthana, S.; Vertrees, J.E.; Pallaki, M.; Llorente, M.; Love, S.; Schellenberg, G. Impact of apolipoprotein E genotypes on vitamin E and memantine treatment outcomes in Alzheimer's disease. Alzheimers Dement. (N.Y.) 2018, 4, 344-349. [CrossRef]

247. Yuan, L.; Liu, J.; Dong, L.; Cai, C.; Wang, S.; Wang, B.; Xiao, R. Effects of APOE rs429358, rs7412 and GSTM1/GSTT1 polymorphism on plasma and erythrocyte antioxidant parameters and cognition in old chinese adults. Nutrients 2015, 7, 8261-8273. [CrossRef]

248. Huebbe, P.; Lodge, J.K.; Rimbach, G. Implications of apolipoprotein E genotype on inflammation and vitamin E status. Mol. Nutr. Food Res. 2010, 54, 623-630. [CrossRef] [PubMed]

249. Jarvik, G.P.; Tsai, N.T.; McKinstry, L.A.; Wani, R.; Brophy, V.H.; Richter, R.J.; Schellenberg, G.D.; Heagerty, P.J.; Hatsukami, T.S.; Furlong, C.E. Vitamin C and Eintake is associated with increased paraoxonase activity. Arterioscler. Thromb. Vasc. Biol. 2002, 22, 1329-1333. [CrossRef] [PubMed]

250. Lou-Bonafonte, J.M.; Gabás-Rivera, C.; Navarro, M.A.; Osada, J. The search for dietary supplements to elevate or activate circulating paraoxonases. Int. J. Mol. Sci. 2017, 18, 416. [CrossRef] [PubMed]

251. Lassnigg, A.; Punz, A.; Barker, R.; Keznickl, P.; Manhart, N.; Roth, E.; Hiesmayr, M. Influence of intravenous vitamin E supplementation in cardiac surgery on oxidative stress: A double-blinded, randomized, controlled study. Br. J. Anaesth. 2003, 90, 148-154. [CrossRef]

252. Neelamegam, M.; Looi, I.; Ng, K.S.; Malavade, S.S. Vitamin E supplementation for preventing recurrent stroke and other vascular events in patients with stroke or transient ischaemic attack. Cochrane Database Syst Rev. 2017. [CrossRef]

253. Hankey, G.J. Vitamin supplementation and stroke prevention. Stroke 2012, 43, 2814-2818. [CrossRef]

254. Cheng, P.; Wang, L.; Ning, S.; Liu, Z.; Lin, H.; Chen, S.; Zhu, J. Vitamin E intake and risk of stroke: A meta-analysis. Br. J. Nutr. 2018, 120, 1181-1188. [CrossRef]

255. Bin, Q.; Hu, X.; Cao, Y.; Gao, F. The role of vitamin E (tocopherol) supplementation in the prevention of stroke. A meta-analysis of 13 randomised controlled trials. Thromb. Haemost. 2011, 105, 579-585. [CrossRef]

256. Schürks, M.; Glynn, R.J.; Rist, P.M.; Tzourio, C.; Kurth, T. Effects of vitamin E on stroke subtypes: Meta-analysis of randomised controlled trials. BMJ 2010, 341. [CrossRef]

(C) 2020 by the authors. Licensee MDPI, Basel, Switzerland. This article is an open access article distributed under the terms and conditions of the Creative Commons Attribution (CC BY) license (http://creativecommons.org/licenses/by/4.0/). 